IZA DP No. 4852

Shutdown Contests in Multi-Plant Firms and Governmental Intervention

Matthias Kräkel

March 2010 


\title{
Shutdown Contests in Multi-Plant Firms and Governmental Intervention
}

\author{
Matthias Kräkel \\ University of Bonn \\ and IZA
}

Discussion Paper No. 4852

March 2010

IZA

P.O. Box 7240

53072 Bonn

Germany

Phone: +49-228-3894-0

Fax: +49-228-3894-180

E-mail: iza@iza.org

\begin{abstract}
Any opinions expressed here are those of the author(s) and not those of IZA. Research published in this series may include views on policy, but the institute itself takes no institutional policy positions.

The Institute for the Study of Labor (IZA) in Bonn is a local and virtual international research center and a place of communication between science, politics and business. IZA is an independent nonprofit organization supported by Deutsche Post Foundation. The center is associated with the University of Bonn and offers a stimulating research environment through its international network, workshops and conferences, data service, project support, research visits and doctoral program. IZA engages in (i) original and internationally competitive research in all fields of labor economics, (ii) development of policy concepts, and (iii) dissemination of research results and concepts to the interested public.
\end{abstract}

IZA Discussion Papers often represent preliminary work and are circulated to encourage discussion. Citation of such a paper should account for its provisional character. A revised version may be available directly from the author. 
IZA Discussion Paper No. 4852

March 2010

\section{ABSTRACT}

\section{Shutdown Contests in Multi-Plant Firms and Governmental Intervention}

When a multi-plant firm must close one unit due to declining demand it can choose between two alternatives. On the one hand, the firm can announce a certain span of time in which the plants are evaluated according to relative performance with the least performing plant being shut down in the end (shutdown contest). On the other hand, the firm can use given information on the plants' productivities and close the least productive unit. This paper analyzes the selection and incentive properties of both alternatives. Multi-plant firms often operate in an international industry. Hence, in a second step we discuss the effects of governmental support for domestic plants on selection efficiency.

JEL Classification: D21, D61, F23, F51, J65

Keywords: auction, collective tournament, plant closing, governmental intervention

Corresponding author:

Matthias Kräkel

Department of Economics

University of Bonn

Adenauerallee 24-42

D-53113 Bonn

Germany

E-mail: m.kraekel@uni-bonn.de

\footnotetext{
* I would like to thank Wei Ding and Anja Schöttner for helpful comments and suggestions. Financial support by the Deutsche Forschungsgemeinschaft (DFG), grant SFB/TR 15 ("Governance and the Efficiency of Economic Systems"), is gratefully acknowledged.
} 


\section{Introduction}

In the 1990s, General Motors (GM) announced to shut down 21 unnamed plants in the next years. ${ }^{1}$ After the announcement, the plants enter a collective tournament with the tournament losers being shut down. The incentives to survive lead to significant extra efforts by all GM factories. In particular, at the end there was a head-to-head competition between the plants in Willow Run (Michigan) and Arlington (Texas). Further closing rounds followed. For example, in November 2005, GM Chief Executive Officer Rick Wagoner declared shutdown of nine plants by $2008 .^{2}$ In June 2009, GM filed for bankruptcy and published a list of 14 plants and three service centers that will be closed by $2012 .{ }^{3}$ Moreover, three locations were set on standby with the option of re-opening when demand goes up. At least one of them will be re-opened when a new small car will be built; however, GM did not specify which of them.

At that time, GM's European subsidiary Opel still faced an uncertain future. An intensive public debate arose on how many and which plants should be closed, whether Opel should be sold and whether the single European governments should try to help their locations to survive. In 2009, the German government strongly favored selling of Opel to Magna International and offered financial aid for the German locations of Opel. ${ }^{4}$ Other European countries become concerned that Germany might protect its domestic plants at the costs of others. The European Commission even publicly warned against protectionism. In November 2009, GM declared not to sell Opel and to keep alive all four German plants, expecting governmental aid up to $\$ 5$ billion. Further European countries like Spain and Britain also promised financial aid to rescue jobs in their domestic plants. In January 2010, GM proclaimed closing of the Opel plant in Antwerp (Belgium). ${ }^{5}$

Besides the case of GM, there are many other examples where a multi-unit

\footnotetext{
${ }^{1}$ See Ward's Auto World (1992) cited by Drago, Garvey and Turnbull (1996).

${ }^{2}$ See Associated Press (2005).

${ }^{3}$ See, for example, Bunkley (2009), Hargreaves (2009).

${ }^{4}$ See Dempsey (2009), Jolly and Dempsey (2009).

${ }^{5}$ See Jolly (2010).
} 
firm plans to close one or several establishments due to declining demand. ${ }^{6}$ In all these cases, the firm has to decide between two different strategies - it can announce either a certain number of unnamed plants that will be shut down after a fixed period (like GM in the 1990s) or a concrete list of plants to be closed (like GM in 2009). Both strategies have advantages but also potential drawbacks. The first strategy allows the firm to organize a collective tournament between the plants in order to close the tournament losers (i.e., the most underperforming plants during the evaluation period). Such shutdown contests elicit extra incentives from the plants' workforces since neither worker wants to lose his job. Often, the closing of a plant dramatically increases the local rate of unemployment in a certain region and, thus, decreases the workers' outside options. This effect would further enhance overall incentives in the collective tournament. As a potential drawback, at the end of the tournament period the firm may observe that the less productive units have performed far better than the more productive ones, ${ }^{7}$ resulting into inefficient plant closing. The second strategy - announcing an explicit list of shutdowns - would ensure closing of the least productive units at the cost of zero extra incentives since there is no tournament. ${ }^{8}$

In this paper, we use a model with two plants that differ in productivity to analyze the circumstances under which the firm prefers either strategy. In addition, we discuss the possibility that the firm is able to separate selection and incentive issues, that is the firm shuts down the less productive plant for sure, but installs a collective tournament as a pure incentive device. From society's perspective, we address the consequences of the firm's strat-

\footnotetext{
${ }^{6}$ For example, in July 2008, Starbucks announced to close 600 of its underperforming shops. In January 2010, the large European drugstore chain Schlecker (with 13,200 shops in 12 European countries) proclaims to shut down 500 locations.

${ }^{7}$ For example, low-productive plants may employ workers with poor qualifications and bad outside options. Especially these workers should have very high incentives to win the plant-closing contest.

${ }^{8}$ Note that both strategies have the disadvantage that announcing future plant closing may induce high-talented workers to change their employer. In our paper, we abstract from this problem. It can be more severe under either strategy. An unnamed list of plants implies that any worker of any firm has a certain incentive to search for a new job, while a concrete list of plant closings gives a reduced number of workers very strong incentives to change their current employer.
} 
egy choice on the likelihood of a selection failure (i.e., the more-productive plant is closed). In a next step, we consider a setting where the two plants are located in different countries and the respective governments can choose actions to protect its domestic plant. The governments can either directly bid for the decision right which plant to close (e.g., by offering the firm a lump-sum payment as financial aid conditional on the survival of the domestic plant) or, if banned by an international competition authority, indirectly support the domestic plant during the shutdown contest (e.g., by a public contract that increases plant profits). ${ }^{9}$ We investigate how such governmental intervention influences selection efficiency when one of the two heterogeneous plants must be closed. ${ }^{10}$

Our results show that if the firm organizes a tournament between the two plants in order to shut down the loser, the impact of plant size on workers' collective effort and, hence, on a plant's winning probability depends on three effects. First, the larger the size of a plant the lower will be the individual incentives of the workers according to the free-rider effect. Second, due to the plants' concave production technologies and the workers' convex cost-ofeffort functions, the more workers are employed by a certain plant the lower should be an individual's contribution to the workforce's collective effort. Therefore, this technology effect goes in the same direction as the free-rider effect. Third, the larger a plant the more workers will contribute a certain amount of effort which increases overall effort supply (quantity effect). When the free-rider effect and the technology effect dominate the quantity effect, the low-productive plant will be more likely to win the collective tournament if it is sufficiently small. On the one hand, lower outside options of the workers that are employed by the low-productive plant also increase the likelihood of a selection failure. On the other hand, higher bargaining power and higher regular profits of the high-productive plant decrease the proba-

\footnotetext{
${ }^{9}$ Anecdotal evidence again comes from the case of Opel. In 2009, the German government ordered 1,101 cars worth 20.5 million euro from their domestic Opel plants, which should be used as staff cars. In 2010, additional 1,046 cars have been ordered from Opel by the German government.

${ }^{10}$ Note that even within a country we may have a similar situation if plants are located in different regions belonging to different regional governments.
} 
bility of a selection failure. Moreover, we have the following trade-off: If the high-productive plant has a large winning probability, selection failures will be rather unlikely. In these situations, the firm will favor the use of a collective tournament to generate extra incentives for both plants. However, this preference just allows for a positive selection failure, which could be excluded if not relying on a collective tournament.

Theoretically, the firm can use the waiting period before executing plant closure to organize a collective tournament without linking the selection decision to the outcome of the tournament. In other words, the firm can announce to shut down the low-productive plant after this period and independently design optimal tournament prizes to induce incentives for the two plants. This alternative guarantees selection efficiency but eliminates extra incentives from closing the tournament loser. The results show that in case of unlimited liability the firm always prefers to separate selection and incentive issues in this way, even if the tournament winner is not verifiable so that one plant is induced to choose inefficiently small efforts whereas the other plant chooses more than efficient effort. However, if workers are protected by limited liability and the winner of the collective tournament is verifiable, the firm will still link plant closing to the tournament outcome given that the plants' regular profits do not differ to much. The larger the high-productive plant's bargaining power the more likely the firm adheres to its plant-closing contest. Intuitively, in that case most of the efficiency gains are distributed to the workers so that the firm is less interested in selection efficiency.

The third part of the paper deals with the problem of governmental intervention, using the initial two-period model where both plants are active in the first period but one plant is closed in the second period. The firm will always demand higher financial aid from the government with the less productive plant since keeping this plant alive in the second period would unambiguously harm the firm. However, if the respective government's costs for unemployed workers are sufficiently large relative to the firm's secondperiod loss in regular profits from closing the more-productive plant, the government of the low-productive plant will win the bidding process. Since expected unemployment costs increase in plant size and decrease in the work- 
ers' reemployment probabilities, a selection failure due to governmental intervention will particularly occur if the low-productive plant is rather large and part of a distressed labor market. When direct bidding for plant closing is prohibited by a competition authority, governments may still support their plants during the collective tournament via indirect subsidies. Now plant size may work into the opposite direction. If the low-productive plant is so large that the free-rider effect becomes dominant, the respective government will decide against subsidizing. It will better save money since it anticipates that the domestic plant's workforce will not really fight in the tournament due to individual free riding.

The paper is organized as follows. The next section summarizes the related work. Section 3 introduces the basic model, which abstracts from governmental intervention. In Section 4, the model is solved. Section 5, addresses the possibility of separating selection and incentive issues. Section 6 focuses on governmental intervention. Section 7 concludes.

\section{Related Literature}

The paper is related to three strands of the literature. First, there are parallels to the work on collective tournaments. Drago, Garvey and Turnbull (1996) point out that there exists a spread between winner and loser prize that induces first best efforts for all heterogeneous workers in a collective tournament with two plants. Gürtler (2006) shows that in the optimal contract the principal will only use this spread and implement first-best incentives if workers are not protected by limited liability. Marino and Zabojnik (2004) discuss profit sharing in teams and tournament competition between these teams as a possible solution to the free-rider problem. If a collective tournament between teams is optimal, then the firm has strong incentives to choose a multidivisional organization with competing divisions. Gürtler (2008) considers a situation where workers have the possibility to win the collective tournament by investing in both productive effort and counterproductive effort that harms the opposing team (sabotage). Since the teams' production technologies are concave and exhibit strict complementarities, 
each team optimally concentrates its sabotage activities against the least productive member of the opposing team. Finally, there is a large literature on group rent-seeking contests; for an overview see Konrad (2009, 124-131).

The second strand of the related literature addresses the problem of plant closing in declining industries. Part of this literature especially investigates the situation of multi-plant firms. The theoretical work focuses on the roles of production costs and plant size. While all models clearly show that within a given class of plant size - less profitable plants exit first, the papers offer partially mixed results on the impact of size. According to Ghemawat and Nalebuff (1985), exit occurs in decreasing order of plant size. However, Whinston (1988) shows that this result does not generally hold in the case of multi-plant firms. Reynolds (1988) analyzes optimal plant closing of two multi-unit duopolists. If the two firms have the same number of plants, they will first shut down the least profitable ones. If the firms do not differ too much in profitability but have different numbers of plants, the firm with the smaller number will begin to close its plants.

Empirical studies on plant closing within multi-unit firms also identify size and profitability as most important selection criteria. Lieberman (1990) considers the U.S. chemical industry. In case of multi-plant firms, small plants have a higher probability to be shut down. When controlling for plant size, firms with larger capacity shares more likely close locations. Deily (1991) analyzes the steel industry in the U.S., where small and less profitable plants are shut down first. Stafford (1991) shows for multi-unit firms in the Cincinatti region that manufacturing plant closure selection is mainly based on lack of profitability and inappropriate plant size. Based on U.K. data, Kirkham and Watts (1997) report that low-profitable plants within multiunit manufacturing firms are more likely to be shut down but appropriate profits do not assure plant survival. Watts and Kirkham (1999) consider data on U.K. multi-plant firms. They find that small locations are shut first. Richbell and Watts (2000) analyze four cases of international multi-unit firms (Hoover, JVC, Siemens, Avesta Sheffield). In each of these cases, one of two plants has to be closed. Interestingly, in two cases the plant is retained that has the same location as the firm's headquarter; in the two other cases 
significant financial aid comes from the government of the plant that wins survival. In their study on the U.S. manufacturing industry, Bernard and Jensen (2007) show that plants of multi-unit firms and of U.S. multinationals are much larger, older and more productive than plants of single-unit firms. After having controlled for these plant characteristics, plants of multi-unit or multinational firms turn out to have a higher shutdown probability than single plants. Hence, firms with multiple heterogeneous units typically adjust production by closing the least profitable locations.

The third class of related literature deals with international competition and governmental intervention. ${ }^{11}$ Brander and Spencer (1985) address the topic of export subsidies for domestic firms. Since subsidizing is rational from a single country's point of view, a subsidy game between two countries will have a prisoners'-dilemma like outcome where both countries decide to support their local firms although they would collectively gain from not subsidizing. Brainard and Martimort (1997) introduce incomplete information into the Brander-Spencer model. They show that asymmetric information undermines the strategic advantage of precommitment via governmental intervention. Dixit and Kyle (1985) analyze the strategic role of governmental intervention concerning market entry, where a firm can either be protected or deterred. Again, a prisoners'-dilemma outcome is possible. Konrad (2000) considers competition in trade that is modeled as an all-pay auction. He shows that in the equilibrium with strategic trade policies the countries are better off than in the equilibrium without governmental intervention. Brainard (1994) considers the case of two firms that compete in an international industry. She highlights the welfare losses that follow from governments aiding their local firms to prevent market exits. As a consequence a socially wasteful order of market exit may arise. Cassing and Hillman (1986) address just the opposite case. In their approach, a declining industry may lead to a decline in governmental support for the domestic shriveling firm, which is less important relative to other local firms and industries. On an aggregate level, the whole declining industry may collapse. All these papers discuss a situation with independent firms that compete against each other

\footnotetext{
${ }^{11}$ For an overview see Brander (1995).
} 
and are supported by their respective governments. However, the papers do not consider the case of a multi-plant firm with a single employer, which takes center stage in this paper.

\section{The Basic Model}

We consider a firm that is owned by employer $E$ and consists of two plants $h$ and $l$. Plant $h$ is more productive than plant $l$ since the former one has high-productive workers ( $h$-type workers) whereas plant $l$ only employs lowproductive ones ( $l$-type workers). ${ }^{12}$ Thus, each plant employs a homogeneous workforce. ${ }^{13}$ The type of the plant and, hence, the type of a worker are common knowledge (e.g., due to formal qualifications or given degrees of schooling). Plant $p(p=h, l)$ consists of $n_{p}>0$ workers of type $p$ so that the two plants may also differ in size. For simplicity all players are assumed to be risk neutral. ${ }^{14}$

Given these initial employment relationships, we focus on two periods in the lifetime of the firm. In each period, an operating plant $p(p=h, l)$ yields regular profits $\Pi_{p}$ with $\Pi_{h}>\Pi_{l}>0$ (i.e., the plant with the more productive workforce has higher profits). These profits are shared between $E$ and the $n_{p}$ workers. The workforce gets the share $\alpha_{p} \in(0,1)$ which is equally distributed among the workers. The part $\left(1-\alpha_{p}\right) \Pi_{p}$ is earned by employer $E$. It is important to emphasize that we do not consider those incentives and optimal contracts that lead to profits $\Pi_{p}$ and their distribution between the workforce and the employer according to $\alpha_{p}$ and $1-\alpha_{p}$, respectively. Instead, we focus on the possible consequences that result from a negative

\footnotetext{
${ }^{12}$ For example, the workforces differ in their human capital endowments.

${ }^{13}$ The simplifying assumption of homogeneous workforces allows to use the same subscript $p$ for the plant type and the corresponding worker type. This assumption sketches a more realistic situation where one plant has more high-productive workers than the other plant.

${ }^{14}$ Since we focus on incentive and selection issues within given employment relationships and do not discuss possible contract offers by employer $E$ it is not important to introduce contractual frictions like risk aversion or limited liability. However, when analyzing endogenously chosen incentives in Section 5 we also discuss the case of limited liability.
} 
shock during the first period for given employment relationships. This shock forces $E$ to shut down one of his two plants at the end of the first period. In the time span from the shock till the end of period one, each worker $p_{i}$ of plant $p\left(p=h, l ; i=1, \ldots, n_{p}\right)$ can choose additional effort $a_{p_{i}} \geq 0$ to influence plant $p$ 's first-period extra profits, denoted by $\pi_{p}$. The extra profits $\pi_{p}$ are not verifiable by a third party so that $E$ cannot use direct incentive schemes (like bonuses) that are contingent on $\pi_{p}$. However, it is verifiable whether plant $h$ has performed better than $l$ (i.e., $\pi_{h}>\pi_{l}$ ) or vice versa (i.e., $\left.\pi_{h}<\pi_{l}\right) .{ }^{15}$ Effort choices cannot be observed by employer $E$ or a third party. Let $A_{p}:=\sum_{i=1}^{n_{p}} a_{p_{i}}$ denote collective extra effort of the workforce in plant $p$. The impact of collective effort on realized profits $\pi_{p}$ is characterized by the cumulative distribution function $F\left(\pi_{p} \mid A_{p}, \gamma_{p}\right)$ with corresponding density $f\left(\pi_{p} \mid A_{p}, \gamma_{p}\right)$ and $\gamma_{p} \in(0,1)$ as productivity parameter where larger values indicate higher productivity.

We make use of the spanning condition introduced by Grossman and Hart (1983) to guarantee well-behaved objective functions for the workers: $F\left(\pi_{p} \mid A_{p}, \gamma_{p}\right)=\gamma_{p} \lambda\left(A_{p}\right) F_{H}\left(\pi_{p}\right)+\left(1-\gamma_{p} \lambda\left(A_{p}\right)\right) F_{L}\left(\pi_{p}\right)$ and $f\left(\pi_{p} \mid A_{p}, \gamma_{p}\right)=$ $\gamma_{p} \lambda\left(A_{p}\right) f_{H}\left(\pi_{p}\right)+\left(1-\gamma_{p} \lambda\left(A_{p}\right)\right) f_{L}\left(\pi_{p}\right)$ with $\lambda\left(A_{p}\right) \in(0,1]$ being strictly increasing, concave and twice differentiable, and $f_{L}\left(\pi_{p}\right) / f_{H}\left(\pi_{p}\right)$ satisfying the monotone likelihood ratio property. The distributions $F_{H}\left(\pi_{p}\right)$ and $F_{L}\left(\pi_{p}\right)$ have different means $\mu_{H}$ and $\mu_{L}\left(<\mu_{H}\right)$, respectively, but the same support $[\underline{\pi}, \bar{\pi}]$. Exerting effort entails costs on a worker described in monetary terms by the function $c\left(a_{p_{i}}\right)$ with $c^{\prime}\left(a_{p_{i}}\right), c^{\prime \prime}\left(a_{p_{i}}\right)>0, \forall a_{p_{i}}>0$, and $c^{\prime}(0)=c(0)=0$. For comparative statics, sometimes we make use of a parameterized version of the model with $\lambda\left(A_{p}\right)=\rho A_{p}(\rho \in(0,1))$ and $c\left(a_{p_{i}}\right)=\frac{\theta}{2} a_{p_{i}}^{2}$ with $\theta>0 .{ }^{16}$

In the second period, the workers of the closed plant $\hat{p} \in\{h, l\}$ get their respective reservation values $\bar{v}_{\hat{p}} \geq 0$. The workers of the other plant

\footnotetext{
${ }^{15}$ That is, a third party only has limited information. It lacks cardinal profit information but can verify ordinal performance. In Section 5, we also consider the case of an unverifiable ranking of extra profits.

${ }^{16}$ To guarantee that $\lambda\left(A_{p}\right) \in(0,1]$ we assume that $\rho$ is sufficiently small and $\theta$ sufficiently large. The assumption of a linear $\lambda(\cdot)$-function is also referred to as the Linear Distribution Function Condition (LDFC); see Hart and Holmström (1987), p. 84.
} 
$p \in\{h, l\} \backslash\{\hat{p}\}$ are still employed by $E$ and realize second-period profits $\Pi_{p}$. Again, these profits $\Pi_{p}$ are shared between the $n_{p}$ workers and employer $E$ according to $\alpha_{p}$ and $1-\alpha_{p}$. We assume that it is more attractive for a worker to be employed by $E$ than to be dismissed: $\frac{\alpha_{\hat{p}}}{n_{\hat{p}}} \Pi_{\hat{p}}>\bar{v}_{\hat{p}}(\hat{p}=h, l)$. Furthermore, we assume that $E$ always prefers to shut down the less productive plant: $\left(1-\alpha_{h}\right) \Pi_{h}>\left(1-\alpha_{l}\right) \Pi_{l}$. Finally, we neglect discounting.

Altogether, the vector $\left(\gamma_{p}, \alpha_{p}, \bar{v}_{p}, \Pi_{p}\right)$ characterizes a $p$-type worker. Let each component of $\left(\gamma_{h}, \alpha_{h}, \bar{v}_{h}, \Pi_{h}\right)$ be larger than the respective component of $\left(\gamma_{l}, \alpha_{l}, \bar{v}_{l}, \Pi_{l}\right)$. Hence, we assume that higher productivity of a worker leads to higher expected extra profits in the first period (given a certain effort level), higher bargaining power, a higher reservation value ${ }^{17}$ and higher regular profits.

Employer $E$ has to choose between two alternatives for the remaining part of period one after the shock: (1) $E$ can organize a collective tournament between plants $h$ and $l$ and shut down the tournament loser after period one (shutdown contest). In that case, $E$ would benefit from the extra incentives generated by the collective tournament. However, since the winner and the loser of the tournament are verifiable, $E$ must close the more productive plant $h$ if the less productive unit $l$ wins the tournament. (2) When the shock occurs, $E$ can decide to shut down the less productive plant $l$ for sure. This alternative would prevent any selection failure at the cost of zero extra incentives. In order to highlight the incentive and selection effects of plantclosing competition we neglect the existence of other possible incentive and selection schemes.

The timing of the model is as follows. First, nature chooses $\left(\gamma_{h}, \alpha_{h}, \bar{v}_{h}, \Pi_{h}\right)$ and $\left(\gamma_{l}, \alpha_{l}, \bar{v}_{l}, \Pi_{l}\right)$ from two probability distributions, with the distribution for $\left(\gamma_{h}, \alpha_{h}, \bar{v}_{h}, \Pi_{h}\right)$ taking strictly higher values than that for $\left(\gamma_{l}, \alpha_{l}, \bar{v}_{l}, \Pi_{l}\right)$. Thereafter, the negative shock occurs and the employer $E$ has do decide whether to organize a collective tournament (alternative (1)) or to shut down plant $l$ for sure (alternative (2)). If $E$ has chosen alternative (1), a collective tournament between plants $h$ and $l$ starts where the workers decide on their

\footnotetext{
${ }^{17}$ Thus, we implicitly assume that a worker's human capital is not completely plantspecific or firm-specific.
} 
optimal effort levels.

\section{Solution to the Basic Model}

\subsection{Shutdown Contest between the Plants}

If $E$ prefers to organize a tournament between plants $h$ and $l$, worker $p_{i}$ of plant $p\left(p=h, l ; i=1, \ldots, n_{p}\right)$ chooses effort to maximize $\mathrm{e}^{18}$

$$
\bar{v}_{p}+\left(\frac{\alpha_{p}}{n_{p}} \Pi_{p}-\bar{v}_{p}\right) \int_{\underline{\pi}}^{\bar{\pi}}\left[1-F\left(\pi_{\hat{p}} \mid A_{p}, \gamma_{p}\right)\right] f\left(\pi_{\hat{p}} \mid A_{\hat{p}}, \gamma_{\hat{p}}\right) d \pi_{\hat{p}}-c\left(a_{p_{i}}\right)
$$

where $\hat{p}$ denotes the other plant. In any case, worker $p_{i}$ has to bear his effort $\operatorname{costs} c\left(a_{p_{i}}\right)$ and receives at least his reservation value $\bar{v}_{p}$ in the second period. With probability $\operatorname{prob}\left\{\pi_{p}>\pi_{\hat{p}}\right\}=\int_{\underline{\pi}}^{\bar{\pi}}\left[1-F\left(\pi_{\hat{p}} \mid A_{p}, \gamma_{p}\right)\right] f\left(\pi_{\hat{p}} \mid A_{\hat{p}}, \gamma_{\hat{p}}\right) d \pi_{\hat{p}}$ plant $p$ wins the tournament so that worker $p_{i}$ is not dismissed and additionally gets $\frac{\alpha_{p}}{n_{p}} \Pi_{p}-\bar{v}_{p}$. From the first-order condition

$$
-\left(\frac{\alpha_{p}}{n_{p}} \Pi_{p}-\bar{v}_{p}\right) \int_{\underline{\pi}}^{\bar{\pi}} \frac{\partial}{\partial a_{p_{i}}} F\left(\pi_{\hat{p}} \mid A_{p}, \gamma_{p}\right) f\left(\pi_{\hat{p}} \mid A_{\hat{p}}, \gamma_{\hat{p}}\right) d \pi_{\hat{p}}-c^{\prime}\left(a_{p_{i}}\right)=0
$$

and the spanning condition we obtain ${ }^{19}$

$$
\begin{gathered}
\gamma_{\hat{p}} \lambda\left(A_{\hat{p}}\right) \int_{\underline{\pi}}^{\bar{\pi}}\left[F_{H}\left(\pi_{\hat{p}}\right)-F_{L}\left(\pi_{\hat{p}}\right)\right]\left[f_{H}\left(\pi_{\hat{p}}\right)-f_{L}\left(\pi_{\hat{p}}\right)\right] d \pi_{\hat{p}} \\
+\int_{\underline{\pi}}^{\bar{\pi}}\left[F_{H}\left(\pi_{\hat{p}}\right)-F_{L}\left(\pi_{\hat{p}}\right)\right] f_{L}\left(\pi_{\hat{p}}\right) d \pi_{\hat{p}}=\frac{c^{\prime}\left(a_{p_{i}}\right)}{-\left(\frac{\alpha_{p}}{n_{p}} \Pi_{p}-\bar{v}_{p}\right) \gamma_{p} \lambda^{\prime}\left(A_{p}\right)} .
\end{gathered}
$$

\footnotetext{
${ }^{18}$ Since regular first-period profits, $\Pi_{p}$, do not influence workers' behavior they can be skipped in the objective function.

${ }^{19}$ Note that the second-order condition is always satisfied.
} 
Note that the first integral is zero:

$$
\begin{gathered}
\int_{\underline{\pi}}^{\bar{\pi}}\left[F_{H}\left(\pi_{\hat{p}}\right)-F_{L}\left(\pi_{\hat{p}}\right)\right]\left[f_{H}\left(\pi_{\hat{p}}\right)-f_{L}\left(\pi_{\hat{p}}\right)\right] d \pi_{\hat{p}} \\
=\int_{\underline{\pi}}^{\bar{\pi}}\left[F_{H}\left(\pi_{\hat{p}}\right) f_{H}\left(\pi_{\hat{p}}\right)+F_{L}\left(\pi_{\hat{p}}\right) f_{L}\left(\pi_{\hat{p}}\right)\right] d \pi_{\hat{p}} \\
-\int_{\underline{\pi}}^{\bar{\pi}}\left[F_{H}\left(\pi_{\hat{p}}\right) f_{L}\left(\pi_{\hat{p}}\right)+F_{L}\left(\pi_{\hat{p}}\right) f_{H}\left(\pi_{\hat{p}}\right)\right] d \pi_{\hat{p}}=0
\end{gathered}
$$

with

$$
\begin{gathered}
\int_{\underline{\pi}}^{\bar{\pi}} F_{X}\left(\pi_{\hat{p}}\right) f_{X}\left(\pi_{\hat{p}}\right) d \pi_{\hat{p}}=\left.F_{X}\left(\pi_{\hat{p}}\right)^{2}\right|_{\underline{\pi}} ^{\bar{\pi}}-\int_{\underline{\pi}}^{\bar{\pi}} f_{X}\left(\pi_{\hat{p}}\right) F_{X}\left(\pi_{\hat{p}}\right) d \pi_{\hat{p}} \\
\Leftrightarrow \int_{\underline{\pi}}^{\bar{\pi}} F_{X}\left(\pi_{\hat{p}}\right) f_{X}\left(\pi_{\hat{p}}\right) d \pi_{\hat{p}}=\frac{1}{2}
\end{gathered}
$$

for $X=H, L$, and

$$
\begin{gathered}
\int_{\underline{\pi}}^{\bar{\pi}} F_{H}\left(\pi_{\hat{p}}\right) f_{L}\left(\pi_{\hat{p}}\right) d \pi_{\hat{p}}=\left.F_{H}\left(\pi_{\hat{p}}\right) F_{L}\left(\pi_{\hat{p}}\right)\right|_{\underline{\pi}} ^{\bar{\pi}}-\int_{\underline{\pi}}^{\bar{\pi}} f_{H}\left(\pi_{\hat{p}}\right) F_{L}\left(\pi_{\hat{p}}\right) d \pi_{\hat{p}} \\
\Leftrightarrow \int_{\underline{\pi}}^{\bar{\pi}}\left[F_{H}\left(\pi_{\hat{p}}\right) f_{L}\left(\pi_{\hat{p}}\right)+F_{L}\left(\pi_{\hat{p}}\right) f_{H}\left(\pi_{\hat{p}}\right)\right] d \pi_{\hat{p}}=1 .
\end{gathered}
$$

Hence, the first-order condition (1) boils down to

$$
-\int_{\underline{\pi}}^{\bar{\pi}}\left[F_{H}\left(\pi_{\hat{p}}\right)-F_{L}\left(\pi_{\hat{p}}\right)\right] f_{L}\left(\pi_{\hat{p}}\right) d \pi_{\hat{p}}=\frac{c^{\prime}\left(a_{p_{i}}\right)}{\left(\frac{\alpha_{p}}{n_{p}} \Pi_{p}-\bar{v}_{p}\right) \gamma_{p} \lambda^{\prime}\left(A_{p}\right)} .
$$

The left-hand side can be rewritten as

$$
\begin{gathered}
-\int_{\underline{\pi}}^{\bar{\pi}}\left[F_{H}\left(\pi_{\hat{p}}\right) f_{L}\left(\pi_{\hat{p}}\right)-F_{L}\left(\pi_{\hat{p}}\right) f_{L}\left(\pi_{\hat{p}}\right)\right] d \pi_{\hat{p}} \\
\stackrel{(3)}{=} \frac{1}{2}-\int_{\underline{\pi}}^{\bar{\pi}} F_{H}\left(\pi_{\hat{p}}\right) f_{L}\left(\pi_{\hat{p}}\right) d \pi_{\hat{p}}=: \Delta F>0
\end{gathered}
$$


where $\Delta F>0$ follows from the monotone likelihood ratio property. ${ }^{20}$ Since from (5) it is obvious that all workers of plant $p$ choose identical efforts, we have the following result:

Proposition 1 In the tournament, each worker of plant $p(p=h, l)$ chooses effort $a_{p}^{*}$ implicitly described by

$$
\left(\frac{\alpha_{p}}{n_{p}} \Pi_{p}-\bar{v}_{p}\right) \gamma_{p} \Delta F \lambda^{\prime}\left(n_{p} a_{p}^{*}\right)=c^{\prime}\left(a_{p}^{*}\right)
$$

with $\partial a_{p}^{*} / \partial n_{p}<0$. Expected extra profits of plant $p$ during period one amount to

$$
\gamma_{p} \lambda\left(n_{p} a_{p}^{*}\right)\left(\mu_{H}-\mu_{L}\right)+\mu_{L}
$$

Plant $p$ wins in the tournament against plant $\hat{p}(p, \hat{p}=h, l ; p \neq \hat{p})$ with probability

$$
P_{p}:=\frac{1}{2}+\left[\gamma_{p} \lambda\left(n_{p} a_{p}^{*}\right)-\gamma_{\hat{p}} \lambda\left(n_{\hat{p}} a_{\hat{p}}^{*}\right)\right] \Delta F
$$

Proof. See Appendix.

Equation (6) shows that a worker's optimal effort increases in his bargaining power $\alpha_{p}$, in the second-period profits $\Pi_{p}$ and in productivity $\gamma_{p}$, but decreases in his reservation value $\bar{v}_{p}$, which defines his fall-back position when his plant loses the collective tournament. Furthermore, optimal effort decreases in the number of co-workers (i.e., $\partial a_{p}^{*} / \partial n_{p}<0$ ). This result is based on two effects. First, there is the well-known free-rider effect indicated by $\frac{\alpha_{p}}{n_{p}} \Pi_{p}$, which arises here because one plant fights as a team against the other plant. Within this fight, marginal extra income from winning the collective tournament decreases in plant size whereas individual marginal costs are not influenced by $n_{p}$. Second, even without incentive problems the workforce would prefer an individual effort level for each worker that decreases in $n_{p}$ for pure technological reasons. This technology effect is indicated by

\footnotetext{
${ }^{20}$ Since the monotone likelihood ratio property implies first-order stochastic dominance (e.g., Wolfstetter 1999, p. 139) we have $\int_{\pi}^{\bar{\pi}} Y\left(\pi_{\hat{p}}\right)\left[f_{H}\left(\pi_{\hat{p}}\right)-f_{L}\left(\pi_{\hat{p}}\right)\right] d \pi_{\hat{p}}>0$ for any increasing function $Y(\cdot)$. Using $Y\left(\pi_{\hat{p}}\right)=\bar{F}_{H}\left(\pi_{\hat{p}}\right)$ and (3), immediately leads to $\int_{\underline{\pi}}^{\bar{\pi}} F_{H}\left(\pi_{\hat{p}}\right) f_{L}\left(\pi_{\hat{p}}\right) d \pi_{\hat{p}}<\frac{1}{2}$.
} 
$\lambda^{\prime}\left(n_{p} a_{p}^{*}\right)$ and arises from the concavity of function $\lambda(\cdot)$ - implying decreasing marginal returns - in connection with a uniform convex cost function for each worker. ${ }^{21}$

Proposition 1 points out that collective effort by the whole workforce of plant $p, n_{p} a_{p}^{*}$, plays a prominent role for the outcome of the tournament. Differentiating collective effort with respect to plant size yields ${ }^{22}$

$$
\frac{\partial}{\partial n_{p}} n_{p} a_{p}^{*}=a_{p}^{*}+\frac{\partial a_{p}^{*}}{\partial n_{p}} .
$$

The expression consists of two terms. The first one, $a_{p}^{*}$, is positive and can be called quantity effect since collective effort will increase by $a_{p}^{*}$ if the number of workers is increased by an additional one. The second term is negative due to the free-rider effect and the technology effect, described in the paragraph before. Without further specifying the underlying functions it is not clear which effect dominates.

Note that according to (8) the more productive plant may have a lower probability of winning the collective tournament than the less productive one (i.e., $\gamma_{h} \lambda\left(n_{h} a_{h}^{*}\right)<\gamma_{l} \lambda\left(n_{l} a_{l}^{*}\right)$ ). In particular, this is possible if productivities $\gamma_{h}$ and $\gamma_{l}$ do not differ too much. If now the free-rider effect and the technology effect dominate (are dominated by) the quantity effect, the more productive plant will be less likely to win the collective tournament than the low productive plant if the former one is sufficiently larger (smaller) than the latter one.

For the parameterized version of the model with $\lambda\left(A_{p}\right)=\rho A_{p}$ and $c\left(a_{p_{i}}\right)=\frac{\theta}{2} a_{p_{i}}^{2}$ we get a clear-cut result. Optimal effort of a worker employed

\footnotetext{
${ }^{21}$ In other words, given a first marginal unit of effort exerted by all workers of plant $p$, the next marginal unit has lower marginal collective returns if $n_{p}+1$ instead of $n_{p}$ workers have exerted the first marginal unit. However, marginal individual costs are identical for all workers of a certain plant and not influenced by $n_{p}$. See also first-best efforts below described by (11).

${ }^{22}$ Although plant size $n_{p}$ is an integer, for simplicity it is treated as being continuous when doing comparative statics.
} 
by plant $p$ is given by

$$
a_{p}^{*}=\left(\frac{\alpha_{p}}{n_{p}} \Pi_{p}-\bar{v}_{p}\right) \frac{\gamma_{p} \rho \Delta F}{\theta}
$$

so that the less productive plant is more likely to survive (i.e., $P_{l}>1 / 2$ ) if and only if

$$
\frac{\gamma_{h}^{2}}{\gamma_{l}^{2}}<\frac{\alpha_{l} \Pi_{l}-n_{l} \bar{v}_{l}}{\alpha_{h} \Pi_{h}-n_{h} \bar{v}_{h}} .
$$

Here, the technology effect is completely eliminated (i.e., marginal returns of $\lambda\left(A_{p}\right)$ are constant) and the free-rider effect dominates the quantity effect so that the more productive plant is less likely to win the collective tournament the larger its workforce.

\subsection{The Employer's Decision}

The employer can either close plant $l$ for sure or select plants via a collective tournament with the loser being shut down. He will prefer a shutdown contest if the resulting expected extra profits plus his expected second-period payoffs exceed his sure second-period payoffs from running plant $h$ :

$$
\begin{aligned}
& \gamma_{h} \lambda\left(n_{h} a_{h}^{*}\right)\left(\mu_{H}-\mu_{L}\right)+\mu_{L}+\gamma_{l} \lambda\left(n_{l} a_{l}^{*}\right)\left(\mu_{H}-\mu_{L}\right)+\mu_{L} \\
& +\left(1-\alpha_{h}\right) \Pi_{h} \cdot P_{h}+\left(1-\alpha_{l}\right) \Pi_{l} \cdot P_{l}>\left(1-\alpha_{h}\right) \Pi_{h} .
\end{aligned}
$$

Rewriting the inequality immediately gives the following result:

Proposition 2 Employer E prefers to organize a shutdown contest between plants $h$ and $l$, if and only if

$$
\begin{gathered}
\left(\frac{1}{2}-\left[\gamma_{h} \lambda\left(n_{h} a_{h}^{*}\right)-\gamma_{l} \lambda\left(n_{l} a_{l}^{*}\right)\right] \Delta F\right)\left[\left(1-\alpha_{h}\right) \Pi_{h}-\left(1-\alpha_{l}\right) \Pi_{l}\right]< \\
{\left[\gamma_{h} \lambda\left(n_{h} a_{h}^{*}\right)+\gamma_{l} \lambda\left(n_{l} a_{l}^{*}\right)\right]\left(\mu_{H}-\mu_{L}\right)+2 \mu_{L} .}
\end{gathered}
$$

The left-hand side shows the expected costs from using a collective tournament: With probability $\frac{1}{2}-\left[\gamma_{h} \lambda\left(n_{h} a_{h}^{*}\right)-\gamma_{l} \lambda\left(n_{l} a_{l}^{*}\right)\right] \Delta F$ plant $l$ wins so 
that E's second-period payoff is $\left(1-\alpha_{l}\right) \Pi_{l}$ instead of $\left(1-\alpha_{h}\right) \Pi_{h}$. The righthand side describes the benefit of additional incentives via the tournament.

There is the following trade-off: The higher the winning probability of plant $h$ (i.e., the higher $\left.\left[\gamma_{h} \lambda\left(n_{h} a_{h}^{*}\right)-\gamma_{l} \lambda\left(n_{l} a_{l}^{*}\right)\right] \Delta F\right)$ the less likely a selection failure when relying on selection via the shutdown contest and, hence, the more likely a contest is used. ${ }^{23}$ However, in case of a contest we still have a positive failure probability, which would not be the case if $E$ forgoes to use a shutdown contest. In other words, the failure probability (i.e., the probability that plant $h$ is closed) may be discontinuous in $\gamma_{h} \lambda\left(n_{h} a_{h}^{*}\right)$ : If $\gamma_{h} \lambda\left(n_{h} a_{h}^{*}\right)$ is very small, then condition (9) will rather not be satisfied and the failure probability is zero. If $\gamma_{h} \lambda\left(n_{h} a_{h}^{*}\right)$ increases and exceeds a certain threshold (implicitly described by $\left(\frac{1}{2}-\left[\gamma_{h} \lambda\left(n_{h} a_{h}^{*}\right)-\gamma_{l} \lambda\left(n_{l} a_{l}^{*}\right)\right] \Delta F\right)[(1-$ $\left.\left.\left.\alpha_{h}\right) \Pi_{h}-\left(1-\alpha_{l}\right) \Pi_{l}\right]=\left[\gamma_{h} \lambda\left(n_{h} a_{h}^{*}\right)+\gamma_{l} \lambda\left(n_{l} a_{l}^{*}\right)\right]\left(\mu_{H}-\mu_{L}\right)+2 \mu_{L}\right)$ condition (9) becomes satisfied so that $E$ now prefers to organize a contest, implying a positive failure probability. If $\gamma_{h} \lambda\left(n_{h} a_{h}^{*}\right)$ further increases, this failure probability will monotonically decrease. ${ }^{24}$

\section{$5 \quad$ Separating Selection and Incentives}

Since the realizations of $\pi_{l}$ and $\pi_{h}$ are unverifiable, employer $E$ cannot write incentive contracts based on extra profits. However, he can use relativecompensation schemes (i.e., rank-order tournaments) as discussed in the section before. In Section 4, selection and incentive issues were strictly interrelated within a shutdown contest: On the one hand, if $E$ wants to make use of extra incentives due to plant-closing competition, the corresponding collective tournament also determines which plant must be closed. On the other hand, if $E$ wants to close the low-productive plant for sure, no extra incentives can arise.

In this section, we analyze the case of separating the selection decision

\footnotetext{
${ }^{23}$ This means, the more likely nature chooses a parameter constellation that satisfies condition (9).

${ }^{24}$ Note that it is also possible that condition (9) even holds when plant $h$ is less likely to win the tournament than plant $l$ (i.e., $\gamma_{h} \lambda\left(n_{h} a_{h}^{*}\right)<\gamma_{l} \lambda\left(n_{l} a_{l}^{*}\right)$ ). Such constellation requires that expected extra profits in period one are sufficiently large.
} 
from the outcome of the tournament so that the tournament can now be optimally designed for generating incentives: Theoretically, when the negative shock occurs employer $E$ can at the same time announce to close plant $l$ at the end of the first period and to give a winner prize $w_{1}$ to plant $p$ and a loser prize $w_{2} \leq w_{1}$ to plant $\hat{p}$ if $\pi_{p}>\pi_{\hat{p}}(p, \hat{p}=h, l ; p \neq \hat{p})$. Tournament prizes are equally shared between the workers of the respective plant. E's announcements ensure optimal plant closing without influencing endogenous tournament incentives. In the following, we will discuss whether $E$ always benefits from such separation of selection and incentives.

We assume that $E$ designs optimal tournaments prizes under the constraint that workers must earn nonnegative expected incomes from participating in the collective tournament. This participation constraint seems realistic as no worker can be forced to accept any additional incentive scheme in case of a negative shock. Given this participation constraint, we distinguish two cases: In Subsection 5.1, we address the case where $E$ can freely choose tournament prizes. Thus, $E$ is allowed to choose even negative prizes as long as workers' expected extra incomes are not negative. Since negative prizes are feasible, we refer to this scenario as the case of unlimited liability. In Subsection 5.2, negative tournament prizes are not allowed so that $E$ cannot charge entrance fees from the workers for participating in the tournament. In other words, workers are protected by limited liability. ${ }^{25}$ In both subsections, we differentiate between two scenarios. First, we consider the situation of the basic model in Section 3 with the ranking of extra profits $\pi_{l}$ and $\pi_{h}$ being verifiable (i.e., the winner of the tournament is verifiable). Second, we analyze the consequences that arise when the profit ranking is not verifiable. To guarantee a strictly concave objection function of employer $E$, we make the technical assumption that $c^{\prime}\left(a_{p}\right) / \lambda^{\prime}\left(n_{p} a_{p}\right)$ is a strictly convex function of $a_{p}$ with $\lambda^{\prime}(0)>0$.

\footnotetext{
${ }^{25}$ Hence, in both subsections, we implicitly assume that workers have already consumed their regular first-period incomes, $\frac{\alpha_{p}}{n_{p}} \Pi_{p}$, which therefore can neither be extracted by negative tournament prizes nor be used for liability purposes.
} 


\subsection{Unlimited Liability}

Before solving the two-stage game with $E$ choosing tournament prizes at stage 1 and a collective tournament for given prizes at stage 2, we compute the workers' first-best efforts as a benchmark solution: Without any incentive problem each worker $p_{i}$ of plant $p(p=h, l)$ maximizes the welfare of his plant consisting of expected extra profits (see (7) in Proposition 1) minus total effort costs. Hence, first-best effort solves

$$
\max _{a_{p_{i}}} \gamma_{p} \lambda\left(\sum_{j=1}^{n_{p}} a_{p_{j}}\right)\left(\mu_{H}-\mu_{L}\right)+\mu_{L}-\sum_{j=1}^{n_{p}} c\left(a_{p_{j}}\right) .
$$

The first-order condition yields ${ }^{26}$

$$
\gamma_{p} \lambda^{\prime}\left(\sum_{j=1}^{n_{p}} a_{p_{j}}\right)\left(\mu_{H}-\mu_{L}\right)=c^{\prime}\left(a_{p_{i}}\right) .
$$

Obviously, first-best effort is identical for all workers of plant $p$ and implicitly described by

$$
\gamma_{p} \lambda^{\prime}\left(n_{p} a_{p}^{F B}\right)\left(\mu_{H}-\mu_{L}\right)=c^{\prime}\left(a_{p}^{F B}\right) .
$$

Now, we can solve the two-stage game where $E$ designs optimal incentives at stage 1 . Note that $E$ will choose type-dependent tournament prizes for both plants: $w_{1}^{p}$ will be the winner prize and $w_{2}^{p}$ the loser prize of plant $p(p=h, l)$. For example, if plant $h$ wins (i.e., $\left.\pi_{h}>\pi_{l}\right)$ its workforce will receive $w_{1}^{h}$ whereas the workers of plant $l$ get $w_{2}^{l}$. Such type-dependent prizes are feasible under the assumptions of the basic model where the winner of the tournament is verifiable. Without verifiable winner or profit ranking, $E$ would ex post optimally declare plant $h(l)$ winner of the tournament if $w_{1}^{h}+w_{2}^{l}<(>) w_{1}^{l}+w_{2}^{h}$ independent of true plant performances in order to save labor costs. Since plants anticipate $E$ 's behavior, incentives would be

\footnotetext{
${ }^{26}$ Since the welfare function per worker is strictly concave the first-order condition is sufficient to describe first-best effort.
} 
completely erased. However, if

$$
w_{1}^{h}+w_{2}^{l}=w_{1}^{l}+w_{2}^{h} \Leftrightarrow w_{1}^{h}-w_{2}^{h}=w_{1}^{l}-w_{2}^{l}
$$

so that the sum of prizes does not depend on the outcome of the tournament, type-dependent prizes would still be feasible even if the identity of the tournament winner (i.e., relative plant performances) were not verifiable. Note that condition (12) only requires that each plant faces the same prize spread. Hence, when designing optimal tournament prizes, type-dependent prizes in combination with (12) leaves more freedom to $E$ than uniform tournament prizes. In the following, we will differentiate between the two cases of verifiable and unverifiable profit ranking.

To see that $E$ typically benefits from type-dependent prizes, let for the moment $n_{h}=n_{l}$ so that a higher productivity of plant $h$ is not outweighed by countervailing technology effects (i.e., we unambiguously have $a_{h}^{F B}>a_{l}^{F B}$ ). In this situation, under uniform tournament prizes $w_{1}=w_{1}^{h}=w_{1}^{l}$ and $w_{2}=$ $w_{2}^{h}=w_{2}^{l}$ the workers of the high-productive plant will always earn positive rents. Due to higher productivity, plant $h$ can achieve the same winning probability in the tournament as plant $l$ at lower effort costs. Hence, if $E$ chooses $\left(w_{1}, w_{2}\right)$ to extract all rents from the workforce of plant $l$, the workers of the other plant $h$ will unambiguously receive positive expected incomes from tournament participation. However, under type-dependent tournament prizes $E$ might optimally fine-tune loser prizes $w_{2}^{h}$ and $w_{2}^{l}$ in order to extract rents of both workforces.

By substituting $\frac{w_{1}^{p}}{n_{p}}$ for $\frac{\alpha_{p}}{n_{p}} \Pi_{p}$ and $\frac{w_{2}^{p}}{n_{p}}$ for $\bar{v}_{p}$ in equation (6), optimal worker behavior in plant $p(p=h, l)$ at stage 2 is characterized by $a_{p}$ with

$$
\frac{w_{1}^{p}-w_{2}^{p}}{n_{p}} \gamma_{p} \Delta F \lambda^{\prime}\left(n_{p} a_{p}\right)=c^{\prime}\left(a_{p}\right)
$$

The participation constraint guarantees that each worker's expected extra 
income from the collective tournament is nonnegative:

$$
\frac{w_{1}^{p}}{n_{p}} \cdot P_{p}+\frac{w_{2}^{p}}{n_{p}} \cdot\left(1-P_{p}\right)-c\left(a_{p}\right) \geq 0 \Leftrightarrow \frac{w_{2}^{p}}{n_{p}}+\frac{w_{1}^{p}-w_{2}^{p}}{n_{p}} \cdot P_{p}-c\left(a_{p}\right) \geq 0
$$

with $P_{p}$ denoting the winning probability of plant $p$ according to equation (8). Recall that expected profits from the collective tournament are given by (7). Hence, if the tournament winner is verifiable, employer $E$ will choose $w_{1}^{h}, w_{2}^{h}, w_{1}^{l}, w_{2}^{l}$ to maximize

$$
\left[\gamma_{h} \lambda\left(n_{h} a_{h}\right)+\gamma_{l} \lambda\left(n_{l} a_{l}\right)\right]\left(\mu_{H}-\mu_{L}\right)+2 \mu_{L}-\left(w_{1}^{h}+w_{2}^{l}\right) P_{h}-\left(w_{1}^{l}+w_{2}^{h}\right) P_{l}
$$

subject to the incentive constraint (13) and the participation constraint (14). If the tournament winner is unverifiable, we have to add constraint (12) to $E$ 's optimization problem. Letting $\left(a_{h}^{*}, a_{l}^{*}\right)$ denote optimal efforts, we get the following results:

Proposition 3 (a) If the tournament winner is verifiable, employer $E$ will implement $a_{p}^{*}=a_{p}^{F B}(p=h, l)$. (b) If the winner of the tournament is unverifiable and $n_{h} \neq n_{l}$, employer $E$ will set optimal incentives so that either $a_{h}^{*}<a_{h}^{F B}$ and $a_{l}^{*}>a_{l}^{F B}$, or $a_{h}^{*}>a_{h}^{F B}$ and $a_{l}^{*}<a_{l}^{F B}$; for $n_{h}=n_{l}$ employer $E$ implements $a_{p}^{*}=a_{p}^{F B}(p=h, l)$. Under both (a) and (b), E prefers separating selection and incentives and announcing closure of plant $l$ to a shutdown contest.

\section{Proof. See Appendix.}

Proposition 3 describes the employer's solution to his incentive problem when plant $l$ is closed for sure and tournament prizes are endogenously chosen. In case of a verifiable tournament winner, first-best efforts are implemented although contestants are heterogeneous. The asymmetric competition between plants $h$ and $l$ can be counterbalanced by appropriately adjusted prizes. Type-dependent prize spreads $w_{1}^{p}-w_{2}^{p}$ are used by $E$ to implement efficient efforts for each plant, whereas type-dependent loser prizes $w_{2}^{p}$ serve as a rent-extraction device. If the tournament winner is unverifiable, the additional restriction (12) forces $E$ to apply the same prize spread to each 
plant. As a consequence, first-best implementation for both plants becomes impossible as long as they differ in size. Since type-dependent loser prizes are again fine-tuned by $E$ to extract all rents from the two plants, he gets the full surplus. Depending on plant productivities $\gamma_{p}(p=h, l)$ and the technology effect mentioned in Subsection 4.1, he therefore chooses the lowest possible distortion from first-best incentives, resulting in one workforce supplying inefficiently small effort and the other workforce inefficiently large effort.

The proposition also compares separation of selection and incentives to combining both via a shutdown contest. In that contest, the exogenously given incentives (i.e., $\left.\frac{\alpha_{p} \Pi_{p}}{n_{p}}-\bar{v}_{p}\right)^{27}$ can be supplemented by optimally chosen winner and loser prizes. The results point out that under unlimited liability of the workers employer $E$ is always better off separating selection and incentives, irrespective of whether the winner of the tournament is verifiable or not. The proof of Proposition 3 shows that, in case of verifiability, both separating and combining lead to first-best incentives, but only separating guarantees closing of plant $l$ for sure. In case of unverifiability, both separating and combining guarantee shutdown of the low-productive plant, but separating generates strictly higher incentives than combining. However, negative tournament prizes seem to be rather unrealistic. The following subsection deals with the more realistic situation of workers that are protected by limited liability.

\subsection{Limited Liability}

Under limited liability, negative tournament prizes are not feasible any longer. The additional restriction $w_{1}^{p}, w_{2}^{p} \geq 0(p=h, l)$ has two direct implications for $E$ 's optimization problem when separating selection from incentives. First, the participation constraint (14) can be neglected: Since $\lambda(0)>0$ and $c(0)=0$, each worker can ensure himself a strictly positive expected income from participating in the tournament and choosing zero effort. In other words, each worker earns a nonnegative rent under the optimal tournament

\footnotetext{
${ }^{27}$ See $(6)$.
} 
design. Second, optimal loser prizes are zero since $w_{2}^{h}$ and $w_{2}^{l}$ increase $E$ 's expected labor costs and decrease workers' incentives (see (13)). Therefore, E's optimization problem boils down to

$$
\begin{gathered}
\max _{w_{1}^{h}, w_{1}^{l} \geq 0}\left[\gamma_{h} \lambda\left(n_{h} a_{h}\right)+\gamma_{l} \lambda\left(n_{l} a_{l}\right)\right]\left(\mu_{H}-\mu_{L}\right)+2 \mu_{L}-w_{1}^{h} P_{h}-w_{1}^{l} P_{l} \\
\text { subject to } \frac{w_{1}^{p}}{n_{p}} \gamma_{p} \Delta F \lambda^{\prime}\left(n_{p} a_{p}\right)=c^{\prime}\left(a_{p}\right) \text { for } p=h, l
\end{gathered}
$$

if the tournament winner is verifiable. Unverifiability of the tournament winner adds condition (12) to E's problem, which immediately implies $w_{1}^{h}=$ $w_{1}^{l}=: w_{1}$. In spite of skipping the participation constraint, the solution to the employer's problem (15) is not trivial since winner prize $w_{1}^{p}$ determines the incentives of workforce $p$ as well as the expected labor costs for both plants (via $P_{h}$ and $P_{l}$ ). Recall that without any further assumption it is not clear whether first-best effort in plant $h$ is larger than that in plant $l$ or vice versa since productivities $\gamma_{p}$ and technology effects may work into opposite directions (see (11)). Hence, in order to guarantee that first-best effort is higher in plant $h$ that in plant $l$ we impose the additional restriction $n_{h}=n_{l}$. Let $\left(a_{h}^{*}, a_{l}^{*}\right)$ denote optimal efforts and $\left(w_{1}^{h *}, w_{1}^{l *}\right)$ the corresponding optimal winner prizes. Then we obtain the following results:

Proposition 4 Let $n_{h}=n_{l}=: n$. (a) If the tournament winner is verifiable, then $E$ will not implement effort combinations $\left(a_{h}^{*}, a_{l}^{*}\right)$ with $a_{h}^{*} \geq a_{h}^{F B}$ and $a_{l}^{*} \leq a_{l}^{F B}$; if $\gamma_{h}-\gamma_{l} \rightarrow 0$ then $a_{p}^{*}<a_{p}^{F B}(p=h, l)$. There exists a cut-off value $\bar{\Pi}$ with $\bar{\Pi}>\frac{1-\alpha_{l}}{1-\alpha_{h}}$ so that $E$ prefers plant selection via a shutdown contest to a separation of selection and incentives if $\frac{\Pi_{h}}{\Pi_{l}} \leq \bar{\Pi}$. (b) If the tournament winner is unverifiable, then $a_{p}^{*}<a_{p}^{F B}(p=h, l)$. Employer $E$ always prefers separation of selection and incentives.

\section{Proof. See Appendix.}

The findings of Proposition 4 clearly differ from those of Proposition 3 (unlimited liability). If the tournament winner is verifiable, now employer $E$ does not implement first-best efforts any longer although he is able to finetune incentives for each type of plant. Under limited liability, the plants' 
workforces earn strictly positive rents. Hence, employer $E$ prefers to distort incentives away from first-best in order to minimize workers' rents. He does not implement excessive effort for the high-productive plant at the cost of inefficiently small effort by workforce $l$. If productivities are rather similar, $E$ unambiguously prefers to induce less than efficient incentives for both plants. As pointed out by Proposition 3(b), in case of an unverifiable tournament winner, $E$ induces first-best incentives under unlimited liability as long as plant sizes are identical. However, according to Proposition 4(b), E benefits from implementing inefficiently low effort levels for both plants if workers are protected by limited liability.

The cases of unlimited liability and limited liability also differ concerning employer E's preferences for a separation of selection and incentive issues. If the tournament winner is unverifiable, the findings of Propositions 3 and 4 coincide. In both propositions, employer $E$ cannot credibly commit to close the tournament loser if selection and incentives are combined via a shutdown contest. This problem completely erases incentives. Hence, it is always better for $E$ to close plant $l$ for sure and implement inefficiently low effort levels by a tournament that is purely used as incentive scheme. However, the results of Propositions 3 and 4 sharply differ, if the tournament winner is verifiable. If workers are protected by limited liability, $E$ will prefer to combine selection and incentives if regular profits $\Pi_{h}$ and $\Pi_{l}$ do not differ too much. In this situation, plant selection is not a great issue but workers' second-period rents from winning the shutdown contest can be very useful to substitute first-period tournament prizes. Thus, by combining selection and incentives via a shutdown contest employer $E$ reduces implementation costs. If this reduction is sufficiently large, the employer will accept the risk to shut down the high-productive plant when losing the tournament. Proposition 4(a) also points out that the stronger the plants differ in their bargaining power the more likely $E$ will rely on a shutdown contest. Intuitively, the larger $\alpha_{h}$ the higher the share in regular profits that goes to workforce $h$ in the second period. Therefore, the employer will be less interested in selection efficiency since most of the efficiency gains are distributed to the workers. 
To sum up, if the tournament winner is verifiable by a third party - as assumed in the basic model - and implementation costs are an important issue, employer $E$ will prefer to use a collective tournament for both selection and creating incentives although he is able to solve the two problems separately. Due to $E$ 's preference in favor of a shutdown contest, again it is possible that $E$ ex-post reacts to the negative shock by closing the high-productive plant.

\section{Governmental Intervention}

In this section, we extend the basic model by introducing two additional players. ${ }^{28}$ We assume that the two plants $h$ and $l$ are located in two different countries with governments $G_{h}$ and $G_{l}$, respectively. Since unemployment of workers leads to costs for $G_{h}$ and $G_{l}$ (e.g., loss of income taxes, pay of unemployment benefits), each of the new players is interested in protecting its plant against being shut down. In particular, we assume that each country has to bear costs $\kappa>0$ per unemployed worker.

Since workers differ in productivity, they are also assumed to differ in their reemployment opportunities: Let $\phi_{p} \in(0,1)$ denote the reemployment probability of a $p$-type worker with $\phi_{h}>\phi_{l}(p=h, l)$; that is with probability $\phi_{p}$ the respective worker immediately gets another job in period 2 without generating costs $\kappa,{ }^{29}$ but with probability $1-\phi_{p}$ the worker remains unemployed during period 2 and entails costs $\kappa$ for government $G_{p} \cdot{ }^{30}$ Altogether, now a $p$-type worker is characterized by the vector $\left(\gamma_{p}, \alpha_{p}, \bar{v}_{p}, \Pi_{p}, \phi_{p}\right)$ with $\left(\gamma_{h}, \alpha_{h}, \bar{v}_{h}, \Pi_{h}, \phi_{h}\right)>\left(\gamma_{l}, \alpha_{l}, \bar{v}_{l}, \Pi_{l}, \phi_{l}\right)$.

We differentiate between two cases. First, we allow that the governments can freely bid for the decision right which plant to be closed, that is a government offers employer $E$ a certain amount of financial aid if the domestic plant is kept and the other plant shut down. Second, such auctioning of

\footnotetext{
${ }^{28}$ Thus, we are back in the setup without endogenous tournament prizes.

${ }^{29}$ In that case, a worker receives his reservation value $\bar{v}_{p}$ at his new employer.

${ }^{30}$ Costs $\kappa$ contain unemployment benefits so that a worker again receives his reservation value $\bar{v}_{p}$ in period 2 . Note that this assumption as well as the assumption that reservation values for period 2 only depend on the worker's type but not on the status of a worker (i.e., employed versus unemployed) are not crucial but only made for simplicity.
} 
decision rights is forbidden (e.g., by an international competition agency) and governments can only assist their respective plants during the collective tournament by using indirect subsidies like public contracts that are given to the plant.

\subsection{Bidding for Plant Closing}

Suppose that condition (9) is satisfied so that in the basic model $E$ would organize a shutdown contest. Now we allow the two governments $G_{h}$ and $G_{l}$ bidding for the right to decide which plant is closed. There are three possible outcomes: Either $E$ accepts $G_{h}$ 's offer and closes plant $l$, or $E$ accepts $G_{l}$ 's offer and closes plant $h$, or $E$ rejects the offers of both governments and runs a collective tournament with the loser being shut down. For his decision between these three alternatives $E$ has to choose bidder-specific reserve prices because acceptance of $G_{h}$ 's bid leads to different consequences than accepting $G_{l}$ 's offer. In the first case, $E$ 's payoff in the second period is $\left(1-\alpha_{h}\right) \Pi_{h}$, whereas in the second case he will earn $\left(1-\alpha_{l}\right) \Pi_{l}$. However, in either case employer $E$ forgoes expected extra profits from running a tournament. Hence, $E$ 's reserve price for government $G_{h}$ is

$$
\begin{aligned}
r_{h}:= & \gamma_{h} \lambda\left(n_{h} a_{h}^{*}\right)\left(\mu_{H}-\mu_{L}\right)+\mu_{L}+\gamma_{l} \lambda\left(n_{l} a_{l}^{*}\right)\left(\mu_{H}-\mu_{L}\right)+\mu_{L} \\
& +\left(1-\alpha_{h}\right) \Pi_{h} \cdot P_{h}+\left(1-\alpha_{l}\right) \Pi_{l} \cdot P_{l}-\left(1-\alpha_{h}\right) \Pi_{h},
\end{aligned}
$$

which is unambiguously positive since inequality (9) for the use of a shutdown contest is satisfied. Rearranging gives

$$
\begin{aligned}
r_{h}= & {\left[\gamma_{h} \lambda\left(n_{h} a_{h}^{*}\right)+\gamma_{l} \lambda\left(n_{l} a_{l}^{*}\right)\right]\left(\mu_{H}-\mu_{L}\right)+2 \mu_{L} } \\
& -P_{l} \cdot\left[\left(1-\alpha_{h}\right) \Pi_{h}-\left(1-\alpha_{l}\right) \Pi_{l}\right] .
\end{aligned}
$$

Analogously, as $E$ 's reserve price for government $G_{l}$ we obtain

$$
\begin{aligned}
r_{l}:= & {\left[\gamma_{h} \lambda\left(n_{h} a_{h}^{*}\right)+\gamma_{l} \lambda\left(n_{l} a_{l}^{*}\right)\right]\left(\mu_{H}-\mu_{L}\right)+2 \mu_{L} } \\
& +P_{h} \cdot\left[\left(1-\alpha_{h}\right) \Pi_{h}-\left(1-\alpha_{l}\right) \Pi_{l}\right]=r_{h}+\left[\left(1-\alpha_{h}\right) \Pi_{h}-\left(1-\alpha_{l}\right) \Pi_{l}\right] .
\end{aligned}
$$


The relation $r_{l}>r_{h}$ immediately follows from the fact that closing plant $h$ has worse consequences for $E$ than closing plant $l$.

In a next step, we have to calculate the willingness-to-pay for each bidder, which is identical to the expected costs from plant closing for the respective government. Hence, $G_{p}$ 's $(p=h, l)$ willingness-to-pay in the auction is given by expected costs

$$
k_{p}:=\left(1-\phi_{p}\right) \kappa n_{p}
$$

Note that both constellations $\left(1-\phi_{h}\right) \kappa n_{h} \lessgtr\left(1-\phi_{l}\right) \kappa n_{l}$ are possible; however, if $n_{l} \geq n_{h}$ then we will unambiguously have $k_{h}<k_{l}$.

Before solving the auction game between $E, G_{h}$ and $G_{l}$, we must further specify the rules of the auction. Note that we have a situation with complete information. Hence, the parties can freely bargain without any friction, which would lead to the same outcome as the following asymmetric English auction with a tie-breaking rule: Bidders $G_{p}$ alternately announce offers $b_{p}(p=h, l)$. Alternate bids must be exceeding in the sense that given $G_{p}$ 's bid $b_{p} \geq r_{p}$, the other bidder $G_{\hat{p}}$ can only offer $b_{\hat{p}} \geq r_{\hat{p}}$ if $b_{\hat{p}}-r_{\hat{p}} \geq b_{p}-r_{p}$. The auction ends if neither bidder wants to increase his offer. The party with the final bid must pay this bid to $E$. If both bidders offer final bids, that is $b_{\hat{p}}-r_{\hat{p}}=b_{p}-r_{p}$, the employer $E$ will sell to the bidder with the higher spread $k_{p}-r_{p}$. The auction leads to the following outcome:

Proposition 5 (a) Let $\left(1-\phi_{l}\right) n_{l}>\left(1-\phi_{h}\right) n_{h}$. If $k_{p}<r_{p}(p=h, l)$, then $E$ still organizes a shutdown contest between the plants. If $k_{p}<r_{p}$ and $k_{\hat{p}}>r_{\hat{p}}(p, \hat{p}=h, l, p \neq \hat{p})$, then government $G_{p}$ will not bid. Government $G_{\hat{p}}$ will bid $r_{\hat{p}}$ and win the auction, if and only if $r_{\hat{p}}<P_{p} \cdot k_{\hat{p}}$; otherwise $E$ will run a contest $(p, \hat{p}=h, l, p \neq \hat{p})$. If $k_{p}>r_{p}(p=h, l)$, then government $G_{l}\left(G_{h}\right)$ will win the auction and pay $k_{h}+\left[\left(1-\alpha_{h}\right) \Pi_{h}-\left(1-\alpha_{l}\right) \Pi_{l}\right]$ $\left(k_{l}-\left[\left(1-\alpha_{h}\right) \Pi_{h}-\left(1-\alpha_{l}\right) \Pi_{l}\right]\right)$ if $k_{l}-r_{l}>(<) k_{h}-r_{h}$.

(b) Let $\left(1-\phi_{h}\right) n_{h}>\left(1-\phi_{l}\right) n_{l}$. If $k_{h}<r_{h}$, then $E$ still organizes a shutdown contest. If $k_{h}>r_{h}$ and $k_{l}<r_{l}$, employer $E$ will run a contest given that $r_{h}>P_{l} \cdot k_{h}$; otherwise government $G_{h}$ becomes active and wins the auction, paying $r_{h}$. If $r_{h}<r_{l}<k_{l}<k_{h}$, then both governments are active in the auction and $G_{h}$ wins with bid $k_{l}-\left[\left(1-\alpha_{h}\right) \Pi_{h}-\left(1-\alpha_{l}\right) \Pi_{l}\right]$. 


\section{Proof. See Appendix.}

If the willingness-to-pay of both governments is low relative to the respective reserve prices, no bidding competition will occur and the less productive plant will win the shutdown contest with positive probability. There are also constellations where only one government bids for the decision right which plant to be closed. In these cases, this government $G_{p}$ knows that the other bidder will drop and, hence, only bids its reserve price $r_{p}$. If $k_{p}>r_{p}(p=h, l)$, both governments will be active in the auction. The successful bidder (i.e., the party with the higher spread $k_{p}-r_{p}$ ) pays his reserve price $r_{p}$ plus the opponent's spread $k_{\hat{p}}-r_{\hat{p}}(p, \hat{p}=h, l ; p \neq \hat{p})$. Most interestingly, if the government of the less productive plant has higher expected costs from plant closing than the other government (i.e., $\left.\left(1-\phi_{l}\right) n_{l}>\left(1-\phi_{h}\right) n_{h}\right)$, there will be cases where the former party asserts itself in the auction so that the more productive plant is closed.

\subsection{Subsidizing Plants in the Shutdown Contest}

If direct bidding for plant closing is not allowed, the two governments may indirectly support their plants by reducing business taxes for certain industries or by offering public contracts, for example. ${ }^{31}$ In the following, we consider such situation and assume that government $G_{p}(p=h, l)$ can either support its domestic plant in the shutdown contest (i.e., choose subsidy $s_{p}=s>0$ ) or not $\left(s_{p}=0\right)$. Subsidies typically lower plants' costs or raise their productivities. Since we do not model the plants' cost functions (excepting labor costs), we will focus on the impact of a subsidy on a plant's productivity. In this subsection, we assume that plant $p$ 's productivity in the shutdown contest is described by $\sigma\left(s_{p}\right) \cdot \gamma_{p}$ (instead of $\gamma_{p}$ ) with $\sigma(\cdot) \in(0,1]$ being monotonically increasing. We consider a two-stage game where the two governments simultaneously decide on subsidizing at stage one. At the second stage, the workers of both plants observe $s_{h}$ and $s_{l}$ and then decide on their

\footnotetext{
${ }^{31}$ Here, we consider temporary support during the collective tournament. Other measures like improving the public infrastructure in certain areas by building a new freeway would also favor a plant $p$ in the next period, thus increasing second-period profits $\Pi_{p}$.
} 
extra efforts $a_{p_{i}}$.

The solution of the second stage is described by Proposition 1 after substituting $\sigma\left(s_{p}\right) \cdot \gamma_{p}$ for $\gamma_{p}$ : Given subsidy $s_{p}$, a worker's optimal effort in plant $p, a_{p}^{*}$, is implicitly described by

$$
\left(\frac{\alpha_{p}}{n_{p}} \Pi_{p}-\bar{v}_{p}\right) \sigma\left(s_{p}\right) \gamma_{p} \Delta F \lambda^{\prime}\left(n_{p} a_{p}^{*}\right)=c^{\prime}\left(a_{p}^{*}\right) .
$$

Plant $p$ wins against plant $\hat{p}(p, \hat{p}=h, l ; p \neq \hat{p})$ with probability

$$
P_{p}\left(s_{p}, s_{\hat{p}}\right)=\frac{1}{2}+\left[\sigma\left(s_{p}\right) \gamma_{p} \lambda\left(n_{p} a_{p}^{*}\left(s_{p}\right)\right)-\sigma\left(s_{\hat{p}}\right) \gamma_{\hat{p}} \lambda\left(n_{\hat{p}} a_{\hat{p}}^{*}\left(s_{\hat{p}}\right)\right)\right] \Delta F .
$$

Here, $a_{p}^{*}=a_{p}^{*}\left(s_{p}\right)$ and $P_{p}=P_{p}\left(s_{p}, s_{\hat{p}}\right)$ indicate that optimal effort and winning probability now depend on the governments' subsidy choices.

At the first stage, government $G_{p}$ minimizes

$$
\left(1-\phi_{p}\right) \kappa n_{p} P_{\hat{p}}\left(s_{\hat{p}}, s_{p}\right)+s_{p}
$$

with $P_{\hat{p}}\left(s_{\hat{p}}, s_{p}\right)$ as plant $\hat{p}$ 's winning probability in the contest. For given $s_{\hat{p}}$, government $G_{p}$ prefers $s_{p}=s$ to $s_{p}=0$ as best response if and only if

$$
\begin{gathered}
\left(1-\phi_{p}\right) \kappa n_{p}\left(\frac{1}{2}+\left[\sigma\left(s_{\hat{p}}\right) \gamma_{\hat{p}} \lambda\left(n_{\hat{p}} a_{\hat{p}}^{*}\left(s_{\hat{p}}\right)\right)-\sigma(s) \gamma_{p} \lambda\left(n_{p} a_{p}^{*}(s)\right)\right] \Delta F\right)+s< \\
\left(1-\phi_{p}\right) \kappa n_{p}\left(\frac{1}{2}+\left[\sigma\left(s_{\hat{p}}\right) \gamma_{\hat{p}} \lambda\left(n_{\hat{p}} a_{\hat{p}}^{*}\left(s_{\hat{p}}\right)\right)-\sigma(0) \gamma_{p} \lambda\left(n_{p} a_{p}^{*}(0)\right)\right] \Delta F\right) .
\end{gathered}
$$

Rewriting the inequality leads to the following result: ${ }^{2}$

Proposition 6 Government $G_{p}(p=h, l)$ will subsidize plant $p$ by investing $s_{p}=s$ if and only if

$$
s<\left(1-\phi_{p}\right) \kappa n_{p} \gamma_{p} \Delta F\left[\sigma(s) \lambda\left(n_{p} a_{p}^{*}(s)\right)-\sigma(0) \lambda\left(n_{p} a_{p}^{*}(0)\right)\right] .
$$

\footnotetext{
${ }^{32}$ For the parameterized case we obtain $\lambda\left(n_{p} a_{p}^{*}\right)=\left(\alpha_{p} \Pi_{p}-n_{p} \bar{v}_{p}\right) \frac{\sigma\left(s_{p}\right) \gamma_{p} \rho^{2} \Delta F}{\theta}$.
} 
For the parameterized version of the model, this condition reads as

$$
s<\left(1-\phi_{p}\right) \kappa n_{p}\left(\alpha_{p} \Pi_{p}-n_{p} \bar{v}_{p}\right) \frac{\gamma_{p}^{2} \rho^{2} \Delta F^{2}}{\theta}\left[\sigma^{2}(s)-\sigma^{2}(0)\right] .
$$

Concerning government $G_{h}$, on the one hand a larger reemployment probability $\left(\phi_{h}>\phi_{l}\right)$ and a larger reservation value of the workers $\left(\bar{v}_{h}>\bar{v}_{l}\right)$ make subsidizing less likely compared to government $G_{l}$. For these reasons, the more productive plant may get less support than the less productive plant, which decreases the survival probability of the more productive plant. On the other hand, a larger productivity $\left(\gamma_{h}>\gamma_{l}\right)$, larger second-period profits $\left(\Pi_{h}>\Pi_{l}\right)$ and a higher bargaining $\left(\alpha_{h}>\alpha_{l}\right)$ power work into the opposite direction.

Conditions (16) and (17) also show the influence of plant size. Again, $\lambda\left(n_{p} a_{p}^{*}(s)\right)$ and $\lambda\left(n_{p} a_{p}^{*}(0)\right)$ indicate the trade-off between the quantity effect on the one side and free-rider and technology effects on the other side when plant size increases. But now, an additional effect arises from the expected costs of plant closing, $k_{p}=\left(1-\phi_{p}\right) \kappa n_{p}$, which increase in plant size (shutdown-costs effect). Using the right-hand side of condition (17) for the parameterized version gives

$$
\frac{\partial R H S(17)}{\partial n_{p}}=\left(\alpha_{p} \Pi_{p}-2 n_{p} \bar{v}_{p}\right) \frac{\left(1-\phi_{p}\right) \kappa \gamma_{p}^{2} \rho^{2} \Delta F^{2}}{\theta}\left[\sigma^{2}(s)-\sigma^{2}(0)\right] .
$$

Thus, for small values of $n_{p}$ the quantity effect and the shutdown-costs effect dominate the free-rider effect so that a large plant is more likely to be supported by the government in its struggle to survive. ${ }^{33}$ However, for large values of $n_{p}$ the free-rider effect becomes dominant so that a large plant gets less support than a small one. Intuitively, if a plant is very large the individual contribution of a single worker for the survival of his plant is negligible. Hence, individual incentives tend to be destroyed so that - on the aggregate plant level - the workforce gives up (i.e., $\lambda\left(n_{p} a_{p}^{*}\left(s_{p}\right)\right)$ becomes negligible). Since the government anticipates this incentive disaster it will prefer to save

\footnotetext{
${ }^{33}$ Recall from Subsection 4.1 that the technology effect is absent in the parameterized version.
} 
money by not subsidizing its domestic plant.

There is a further effect that could be relevant in practice and, therefore, may be integrated into the model: Sometimes a large plant is the main employer in a certain region. If this plant is closed, the regional rate of unemployment will significantly rise. In such situations, the reemployment probability is a monotonically decreasing function of plant size (i.e., $\phi_{p}\left(n_{p}\right)$ with $\left.\phi_{p}^{\prime}\left(n_{p}\right)<0\right)$. This additional effect from regional labor markets would make large plants more likely to be supported by the government in an international struggle of plant closing.

\section{Conclusion}

In this paper, we analyze plant closing in a multi-unit firm. In particular, we compare plant closing via a shutdown contest with deterministic closing of the least productive unit. A shutdown contest involves the possibility of a selection failure (i.e., the more productive plant is closed), but offers the opportunity to create additional incentives. If these incentive issues - including the reduction of implementation costs in case of endogenous tournament prizes and limitedly liable workers - dominate selection issues, the firm will prefer organizing a shutdown contest.

If the multi-plant firm operates internationally, political interventions of different governments that try to help their domestic plants may be only one of several interesting topics. The national context of the different plants can influence the firm's closing decision even without any governmental intervention. If, for example, in one country unions have a strong impact on wages, a rather productive plant located in that country may have a higher probability of being shut down than a low-productive plant with less unionized workers. This aspect is also shown in the model discussed in the paper since the workers' bargaining power can be interpreted as a measure of unionization. Then it becomes clear that strong unionization may distort the firm's closing decision away from selection efficiency since a significant part of the corresponding efficiency gains is distributed to the workers. The closing decision may also be influenced by network effects, not incorporated in the given 
model. ${ }^{34}$ In particular, the location of a firm's headquarter can have a large impact on the plant-closing decision. ${ }^{35}$

For simplicity, information problems have been largely ignored in this paper in order to focus on the key arguments for or against a shutdown contest. Of course, incomplete information about the plants' types can either increase or reduce the attractiveness of a shutdown contest from the firm's viewpoint. If, on the one hand, the firm is poorly informed about the true productivities of the different plants, a shutdown contest may be optimal for both incentive and selection purposes. On the other hand, if the governments have information deficits when trying to support their domestic plants in the shutdown contest, competition may be highly distorted by asymmetric information, thus increasing the probability of a selection failure.

\footnotetext{
${ }^{34}$ For example, following the approach by Wintrobe and Breton (1986) managers may be primarily interested to protect their investments in trust, thus distorting selection efficiency.

${ }^{35}$ For anecdotal evidence on the influence of labor unions and the location of the headquarter on the plant-closing decision see the cases reported by Richbell and Watts (2000).
} 


\section{Appendix}

Proof of Proposition 1:

(6) directly follows from (5) by substituting

$$
-\int_{\underline{\pi}}^{\bar{\pi}}\left[F_{H}\left(\pi_{\hat{p}}\right) f_{L}\left(\pi_{\hat{p}}\right)-F_{L}\left(\pi_{\hat{p}}\right) f_{L}\left(\pi_{\hat{p}}\right)\right] d \pi_{\hat{p}}=\Delta F
$$

and $a_{p}^{*}=a_{p_{i}}\left(i=1, \ldots, n_{p}\right)$ so that $A=n_{p} a_{p}^{*}$. Implicitly differentiating (6) with respect to $n_{p}$ yields

$$
\frac{\partial a_{p}^{*}}{\partial n_{p}}=\frac{-\frac{\alpha_{p}}{n_{p}^{2}} \Pi_{p} \lambda^{\prime}\left(n_{p} a_{p}^{*}\right)+\left(\frac{\alpha_{p}}{n_{p}} \Pi_{p}-\bar{v}_{p}\right) \lambda^{\prime \prime}\left(n_{p} a_{p}^{*}\right) a_{p}^{*}}{-\left[\left(\frac{\alpha_{p}}{n_{p}} \Pi_{p}-\bar{v}_{p}\right) \gamma_{p} \Delta F \lambda^{\prime \prime}\left(n_{p} a_{p}^{*}\right) n_{p}-c^{\prime \prime}\left(a_{p}^{*}\right)\right]} \gamma_{p} \Delta F<0
$$

since $\lambda(\cdot)$ is concave and $c(\cdot)$ is convex.

Expected extra profits of plant $p$ in period one can be computed as

$$
\begin{aligned}
\int_{\underline{\pi}}^{\bar{\pi}} \pi_{p} f\left(\pi_{p} \mid a_{p}^{*}\right) d \pi_{p} & =\int_{\underline{\pi}}^{\bar{\pi}} \pi_{p}\left[\gamma_{p} \lambda\left(n_{p} a_{p}^{*}\right)\left[f_{H}\left(\pi_{p}\right)-f_{L}\left(\pi_{p}\right)\right]+f_{L}\left(\pi_{p}\right)\right] d \pi_{p} \\
& =\gamma_{p} \lambda\left(n_{p} a_{p}^{*}\right)\left(\mu_{H}-\mu_{L}\right)+\mu_{L} .
\end{aligned}
$$

Plant h's probability of winning the shutdown contest is given by

$$
\begin{aligned}
& \int_{\underline{\pi}}^{\bar{\pi}}\left[1-F\left(\pi_{l} \mid n_{h} a_{h}^{*}\right)\right] f\left(\pi_{l} \mid n_{l} a_{l}^{*}\right) d \pi_{l}=1-\int_{\underline{\pi}}^{\bar{\pi}} F\left(\pi_{l} \mid n_{h} a_{h}^{*}\right) f\left(\pi_{l} \mid n_{l} a_{l}^{*}\right) d \pi_{l} \\
= & 1-\underbrace{\int_{\underline{\pi}}^{\bar{\pi}} F_{L}\left(\pi_{l}\right) f_{L}\left(\pi_{l}\right) d \pi_{l}}_{=\frac{1}{2} \text { due to }(3)} \\
& -\gamma_{l} \gamma_{h} \lambda\left(n_{l} a_{l}^{*}\right) \lambda\left(n_{h} a_{h}^{*}\right) \underbrace{\int_{\underline{\pi}}^{\bar{\pi}}\left[F_{H}\left(\pi_{l}\right)-F_{L}\left(\pi_{l}\right)\right]\left[f_{H}\left(\pi_{l}\right)-f_{L}\left(\pi_{l}\right)\right] d \pi_{l}}_{=0 \text { due to }(2)} \\
& -\gamma_{h} \lambda\left(n_{h} a_{h}^{*}\right) \int_{\frac{\pi}{\bar{\pi}}}^{\bar{\pi}}\left[F_{H}\left(\pi_{l}\right)-F_{L}\left(\pi_{l}\right)\right] f_{L}\left(\pi_{l}\right) d \pi_{l} \\
& -\gamma_{l} \lambda\left(n_{l} a_{l}^{*}\right) \int_{\underline{\pi}}^{\bar{\pi}} F_{L}\left(\pi_{l}\right)\left[f_{H}\left(\pi_{l}\right)-f_{L}\left(\pi_{l}\right)\right] d \pi_{l} .
\end{aligned}
$$


Hence, it boils down to

$$
\begin{aligned}
& \frac{1}{2}-\gamma_{h} \lambda\left(n_{h} a_{h}^{*}\right)(\int_{\underline{\pi}}^{\bar{\pi}} F_{H}\left(\pi_{l}\right) f_{L}\left(\pi_{l}\right) d \pi_{l}-\underbrace{\int_{\underline{\pi}}^{\bar{\pi}} F_{L}\left(\pi_{l}\right) f_{L}\left(\pi_{l}\right) d \pi_{l}}_{=\frac{1}{2} \text { due to }(3)}) \\
& -\gamma_{l} \lambda\left(n_{l} a_{l}^{*}\right)(\int_{\underline{\pi}}^{\bar{\pi}} F_{L}\left(\pi_{l}\right) f_{H}\left(\pi_{l}\right) d \pi_{l}-\underbrace{\left.\int_{\bar{\pi}}^{\bar{\pi}} F_{L}\left(\pi_{l}\right) f_{L}\left(\pi_{l}\right) d \pi_{l}\right)}_{=\frac{1}{2} \text { due to }(3)} .
\end{aligned}
$$

Using

$$
\int_{\underline{\pi}}^{\bar{\pi}} F_{L}\left(\pi_{l}\right) f_{H}\left(\pi_{l}\right) d \pi_{l}=1-\int_{\underline{\pi}}^{\bar{\pi}} F_{H}\left(\pi_{l}\right) f_{L}\left(\pi_{l}\right) d \pi_{l} .
$$

according to (4), plant $h$ 's winning probability can finally be written as

$$
\begin{aligned}
& \frac{1}{2}+\left[\gamma_{h} \lambda\left(n_{h} a_{h}^{*}\right)-\gamma_{l} \lambda\left(n_{l} a_{l}^{*}\right)\right]\left[\frac{1}{2}-\int_{\underline{\pi}}^{\bar{\pi}} F_{H}\left(\pi_{l}\right) f_{L}\left(\pi_{l}\right) d \pi_{l}\right] \\
= & \frac{1}{2}+\left[\gamma_{h} \lambda\left(n_{h} a_{h}^{*}\right)-\gamma_{l} \lambda\left(n_{l} a_{l}^{*}\right)\right] \Delta F .
\end{aligned}
$$

Therefore, plant l's winning probability is given by

$$
\frac{1}{2}\left[\gamma_{l} \lambda\left(n_{l} a_{l}^{*}\right)-\gamma_{h} \lambda\left(n_{h} a_{h}^{*}\right)\right] \Delta F .
$$


Proof of Proposition 3:

(a) Expected labor costs can be rewritten as follows:

$$
\left(w_{1}^{h}+w_{2}^{l}\right) P_{h}+\left(w_{1}^{l}+w_{2}^{h}\right) P_{l}=w_{2}^{h}+\left(w_{1}^{h}-w_{2}^{h}\right) P_{h}+w_{2}^{l}+\left(w_{1}^{l}-w_{2}^{l}\right) P_{l} .
$$

Hence, E's maximizes

$$
\left[\gamma_{h} \lambda\left(n_{h} a_{h}\right)+\gamma_{l} \lambda\left(n_{l} a_{l}\right)\right]\left(\mu_{H}-\mu_{L}\right)+2 \mu_{L}-w_{2}^{h}-\left(w_{1}^{h}-w_{2}^{h}\right) P_{h}-w_{2}^{l}-\left(w_{1}^{l}-w_{2}^{l}\right) P_{l}
$$

subject to (13) and (14). At the optimum, the workers' participation constraints will be binding: Since loser prizes $w_{2}^{p}$ decrease incentives and increase labor costs, $E$ optimally chooses minimum possible loser prizes that make (14) just bind:

$$
\frac{w_{2}^{p}}{n_{p}}+\frac{w_{1}^{p}-w_{2}^{p}}{n_{p}} P_{p}-c\left(a_{p}\right)=0 \Leftrightarrow w_{2}^{p}+\left(w_{1}^{p}-w_{2}^{p}\right) P_{p}=n_{p} c\left(a_{p}\right) .
$$

Inserting into $E$ 's objective function shows that the employer optimally chooses $w_{1}^{p}-w_{2}^{p}$ in (13) to implement efforts $a_{p}^{*}$ that maximize

$$
\left[\gamma_{h} \lambda\left(n_{h} a_{h}\right)+\gamma_{l} \lambda\left(n_{l} a_{l}\right)\right]\left(\mu_{H}-\mu_{L}\right)+2 \mu_{L}-n_{h} c\left(a_{h}\right)-n_{l} c\left(a_{l}\right)
$$

The first-order conditions for $a_{h}^{*}$ and $a_{l}^{*}$ coincide with equation (11), which characterizes first-best efforts.

(b) If the tournament winner is not verifiable, constraint (12) forces $E$ to apply the same prize spread $\Delta w:=w_{1}^{h}-w_{2}^{h}=w_{1}^{l}-w_{2}^{l}$ to each workforce. Therefore, E's problem can be written as

$$
\begin{gathered}
\max _{\Delta w, w_{2}^{h}, w_{2}^{l}}\left[\gamma_{h} \lambda\left(n_{h} a_{h}\right)+\gamma_{l} \lambda\left(n_{l} a_{l}\right)\right]\left(\mu_{H}-\mu_{L}\right)+2 \mu_{L}-w_{2}^{h}-\Delta w P_{h}-w_{2}^{l}-\Delta w P_{l} \\
\text { subject to } \quad \frac{\Delta w}{n_{p}} \gamma_{p} \Delta F \lambda^{\prime}\left(n_{p} a_{p}\right)=c^{\prime}\left(a_{p}\right) \\
\frac{w_{2}^{p}}{n_{p}}+\frac{\Delta w}{n_{p}} P_{p}-c\left(a_{p}\right) \geq 0 \Leftrightarrow w_{2}^{p}+\Delta w P_{p} \geq n_{p} c\left(a_{p}\right) \quad \text { for } p=h, l
\end{gathered}
$$

Incentive constraint (18) shows that the uniform prize spread $\Delta w$ prevents 
$E$ from fine-tuning both workforces' incentives independently of each other. This restriction does not prevent first-best implementation as long as plants employ the same number of workers $\left(n_{h}=n_{l}\right)$. If plants differ in size (i.e., $n_{h} \neq n_{l}$ ) overall first-best implementation becomes impossible (compare (11) and (18)). However, $E$ can still use type-dependent loser prizes $w_{2}^{l}$ and $w_{2}^{h}$ to extract all rents from the two workforces and make participation constraints (19) bind. Inserting $w_{2}^{p}+\Delta w P_{p}=n_{p} c\left(a_{p}\right)(p=h, l)$ into $E$ 's objective function and combining the incentive constraints (18) for both plants leads to the Lagrangian

$$
\begin{aligned}
L\left(a_{h}, a_{l}\right)= & {\left[\gamma_{h} \lambda\left(n_{h} a_{h}\right)+\gamma_{l} \lambda\left(n_{l} a_{l}\right)\right]\left(\mu_{H}-\mu_{L}\right)+2 \mu_{L} } \\
& -n_{h} c\left(a_{h}\right)-n_{l} c\left(a_{l}\right)+\eta \cdot\left(\frac{n_{h} c^{\prime}\left(a_{h}\right)}{\gamma_{h} \lambda^{\prime}\left(n_{h} a_{h}\right)}-\frac{n_{l} c^{\prime}\left(a_{l}\right)}{\gamma_{l} \lambda^{\prime}\left(n_{l} a_{l}\right)}\right) .
\end{aligned}
$$

with $\eta$ as multiplier. The optimality conditions $\partial L / \partial a_{h}=0$ and $\partial L / \partial a_{l}=0$ yield

$$
\begin{aligned}
\gamma_{h} \lambda^{\prime}\left(n_{h} a_{h}\right)\left(\mu_{H}-\mu_{L}\right)-c^{\prime}\left(a_{h}\right) & =-\frac{\eta}{\gamma_{h}} \frac{\partial}{\partial a_{h}}\left(\frac{c^{\prime}\left(a_{h}\right)}{\lambda^{\prime}\left(n_{h} a_{h}\right)}\right) \\
\gamma_{l} \lambda^{\prime}\left(n_{l} a_{l}\right)\left(\mu_{H}-\mu_{L}\right)-c^{\prime}\left(a_{l}\right) & =\frac{\eta}{\gamma_{l}} \frac{\partial}{\partial a_{l}}\left(\frac{c^{\prime}\left(a_{l}\right)}{\lambda^{\prime}\left(n_{l} a_{l}\right)}\right)
\end{aligned}
$$

subject to

$$
\frac{n_{h} c^{\prime}\left(a_{h}\right)}{\gamma_{h} \lambda^{\prime}\left(n_{h} a_{h}\right)}=\frac{n_{l} c^{\prime}\left(a_{l}\right)}{\gamma_{l} \lambda^{\prime}\left(n_{l} a_{l}\right)} .
$$

The left-hand sides of (20) and (21) are identical to the derivatives of the firstbest plant welfare functions (10) under symmetric worker behavior. If these derivatives become zero they will describe first-best efforts $a_{p}^{F B}$ (see (11)) since the plant welfare functions (10) are strictly concave. Thus, if $\eta<0$ the right-hand side of equation (20) (of equation (21)) is positive (negative), implying that $a_{h}^{*}<a_{h}^{F B}$ and $a_{l}^{*}>a_{l}^{F B}$. Analogously, $\eta>0$ corresponds to $a_{h}^{*}>a_{h}^{F B}$ and $a_{l}^{*}<a_{l}^{F B}$.

If the tournament winner is verifiable, separation of selection and incentives ensures optimal plant closing and induces first-best efforts with $E$ receiving total first-best surplus (see above). In case of combining selection 
and incentives via a shutdown contest (i.e., the tournament loser is closed), $E$ can supplement exogenously given incentives $\frac{\alpha_{p}}{n_{p}} \Pi_{p}-\bar{v}_{p}$ by additional endogenous tournament prizes $w_{1}^{p}$ and $w_{2}^{p}(p=h, l)$ to solve

$$
\begin{aligned}
\max _{w_{1}^{h}, w_{2}^{h}, w_{1}^{l}, w_{2}^{l}}[ & \left.\gamma_{h} \lambda\left(n_{h} a_{h}\right)+\gamma_{l} \lambda\left(n_{l} a_{l}\right)\right]\left(\mu_{H}-\mu_{L}\right)+2 \mu_{L} \\
& -w_{2}^{h}-\left(w_{1}^{h}-w_{2}^{h}\right) P_{h}-w_{2}^{l}-\left(w_{1}^{l}-w_{2}^{l}\right) P_{l}
\end{aligned}
$$

subject to participation constraint (14) and incentive constraint

$$
\left(\frac{\alpha_{p} \Pi_{p}+w_{1}^{p}-w_{2}^{p}}{n_{p}}-\bar{v}_{p}\right) \gamma_{p} \Delta F \lambda^{\prime}\left(n_{p} a_{p}\right)=c^{\prime}\left(a_{p}\right) .
$$

Obviously, from a pure incentive perspective we get the same outcome as under separation: Now, $E$ chooses prize spreads $w_{1}^{p}-w_{2}^{p} \gtrless 0$ according to $\left(\frac{\alpha_{p} \Pi_{p}+w_{1}^{p}-w_{2}^{p}}{n_{p}}-\bar{v}_{p}\right) \Delta F=\left(\mu_{H}-\mu_{L}\right)$ in order to implement first-best efforts (compare (11) and (23)) and loser prizes $w_{2}^{p}$ that make (14) just bind; hence, the employer fully extracts workers' rents. However, under a shutdown contest the less productive plant $l$ is only closed with probability smaller than one. Hence, altogether $E$ is better off when separating selection and incentives.

If the tournament winner is unverifiable, separation again leads to optimal plant closing for sure, but now $E$ induces inefficient incentives (see above). Under a shutdown contest, the low-productive plant will also be closed for sure: Since the tournament winner is not verifiable, $E$ will ex-post always claim that plant $h$ has performed better. However, as this optimal behavior of the employer is anticipated by both workforces, the shutdown contest yields zero incentives - independent of the supplementary tournament prizes $w_{1}^{p}$ and $w_{2}^{p}$. Altogether, employer $E$ again prefers separation of selection and incentives. 
Proof of Proposition 4:

(a) Inserting $w_{1}^{p}=\frac{n c^{\prime}\left(a_{p}\right)}{\gamma_{p} \Delta F \lambda^{\prime}\left(n a_{p}\right)}(p=h, l)$ into the employer's objective function (15) shows that $E$ implements effort levels $\left(a_{h}^{*}, a_{l}^{*}\right)$ that maximize

$\Pi:=\left[\gamma_{h} \lambda\left(n a_{h}\right)+\gamma_{l} \lambda\left(n a_{l}\right)\right]\left(\mu_{H}-\mu_{L}\right)+2 \mu_{L}-\frac{n}{\Delta F}\left(\frac{c^{\prime}\left(a_{h}\right) P_{h}}{\gamma_{h} \lambda^{\prime}\left(n a_{h}\right)}+\frac{c^{\prime}\left(a_{l}\right) P_{l}}{\gamma_{l} \lambda^{\prime}\left(n a_{l}\right)}\right)$.

The optimal effort levels $a_{h}^{*}$ and $a_{l}^{*}$ must satisfy

$$
\begin{gathered}
\frac{\partial \Pi}{\partial a_{h}}=0 \Leftrightarrow \\
\gamma_{h} \lambda^{\prime}\left(n a_{h}\right) n\left[\left(\mu_{H}-\mu_{L}\right)+\frac{n c^{\prime}\left(a_{l}\right)}{\gamma_{l} \lambda^{\prime}\left(n a_{l}\right)}-\frac{n c^{\prime}\left(a_{h}\right)}{\gamma_{h} \lambda^{\prime}\left(n a_{h}\right)}\right]-\frac{n P_{h} \frac{\partial}{\partial a_{h}}\left(\frac{c^{\prime}\left(a_{h}\right)}{\lambda^{\prime}\left(n a_{h}\right)}\right)}{\gamma_{h} \Delta F}=0 \Leftrightarrow \\
\gamma_{h} \lambda^{\prime}\left(n a_{h}\right)\left[\left(\mu_{H}-\mu_{L}\right)+\left(w_{1}^{l}-w_{1}^{h}\right) \Delta F\right]=c^{\prime}\left(a_{h}\right) \frac{P_{h} \Psi\left(a_{h}\right)}{\gamma_{h} \Delta F}
\end{gathered}
$$

and

$$
\frac{\partial \Pi}{\partial a_{l}}=0 \Leftrightarrow \gamma_{l} \lambda^{\prime}\left(n a_{l}\right)\left[\left(\mu_{H}-\mu_{L}\right)+\left(w_{1}^{h}-w_{1}^{l}\right) \Delta F\right]=c^{\prime}\left(a_{l}\right) \frac{P_{l} \Psi\left(a_{l}\right)}{\gamma_{l} \Delta F}
$$

with

$$
\Psi(a):=\frac{c^{\prime \prime}(a)}{c^{\prime}(a) \lambda^{\prime}(n a)}-\frac{\lambda^{\prime \prime}(n a) n}{\left[\lambda^{\prime}(n a)\right]^{2}} .
$$

To prove that $a_{h}^{*} \geq a_{h}^{F B}$ and $a_{l}^{*} \leq a_{l}^{F B}$ cannot be true at the same time, we can apply the following lemma, which will also be useful for proving result (b):

Lemma 1 For any effort level $a>0$ we have $\Psi(a)>1$.

Proof. Since $c^{\prime}(a) / \lambda^{\prime}(n a)$ is a strictly convex function of $a$, we must have that

$$
\frac{\partial}{\partial a}\left(\frac{c^{\prime}(a)}{\lambda^{\prime}(n a)}\right) \cdot a>\frac{c^{\prime}(a)}{\lambda^{\prime}(n a)} \Leftrightarrow \frac{c^{\prime \prime}(a)}{c^{\prime}(a) \lambda^{\prime}(n a)}-\frac{\lambda^{\prime \prime}(n a) n}{\left[\lambda^{\prime}(n a)\right]^{2}}>\frac{1}{a \lambda^{\prime}(n a)} .
$$

Hence, to prove the lemma it suffices to show that $a \cdot \lambda^{\prime}(n a)<1$. Recall that $\lambda(A)$ is assumed to be concave, which implies $\lambda^{\prime}(A) \cdot A \leq \lambda(A)$. For 
$A=n a$ this inequality reads as $\lambda^{\prime}(n a) \cdot n a \leq \lambda(n a)$. Rewriting and using the fact that $\lambda(A) \in(0,1]$ gives

$$
\lambda^{\prime}(n a) \leq \frac{\lambda(n a)}{n a} \leq \frac{1}{n a}<\frac{1}{a}
$$

which completes the proof.

The first part of result (a) can be shown by contradiction. Suppose that $a_{h}^{*} \geq a_{h}^{F B}$ and $a_{l}^{*} \leq a_{l}^{F B}$. In that case, the right-hand side of (25) is larger than $c^{\prime}\left(a_{h}\right)$, because $\gamma_{h} \Delta F<\frac{1}{2}, P_{h}=\frac{1}{2}+\left[\gamma_{h} \lambda\left(n a_{h}^{*}\right)-\gamma_{l} \lambda\left(n a_{l}^{*}\right)\right] \Delta F>\frac{1}{2}$ for $a_{h}^{*}>a_{l}^{*}$, and $\Psi\left(a_{h}\right)>1$ according to Lemma 1 . Since

$$
\left(w_{1}^{l}-w_{1}^{h}\right) \Delta F=n\left(\frac{c^{\prime}\left(a_{l}\right)}{\gamma_{l} \lambda^{\prime}\left(n a_{l}\right)}-\frac{c^{\prime}\left(a_{h}\right)}{\gamma_{h} \lambda^{\prime}\left(n a_{h}\right)}\right)
$$

is zero for $a_{h}=a_{h}^{F B}$ and $a_{l}=a_{l}^{F B}$ according to (11), and strictly negative for $a_{h}>a_{h}^{F B}$ and $a_{l}<a_{l}^{F B}$, the left-hand side of equation (25) is equal to or smaller than $\gamma_{h} \lambda^{\prime}\left(n a_{h}\right)\left(\mu_{H}-\mu_{L}\right)$. As $\lambda(\cdot)$ is concave and $c(\cdot)$ convex, comparison of (11) and (25) immediately shows that we must have $a_{h}^{*}<a_{h}^{F B}$, which contradicts $a_{h}^{*} \geq a_{h}^{F B}$ and $a_{l}^{*} \leq a_{l}^{F B}$.

If $\gamma_{h}-\gamma_{l} \rightarrow 0$ then $\left|w_{1}^{h *}-w_{1}^{l *}\right| \rightarrow 0$ so that the left-hand sides of (25) and (26) simplify to $\gamma_{p} \lambda^{\prime}\left(n a_{p}^{*}\right)\left(\mu_{H}-\mu_{L}\right)(p=h, l)$ whereas the right-hand sides are still strictly larger than $c^{\prime}\left(a_{p}^{*}\right)$, which implies $a_{p}^{*}<a_{p}^{F B}$.

Finally, consider $E$ 's decision on whether separating selection and incentives or not for the case of a verifiable tournament winner. If, on the one hand, $E$ separates selection and incentives, his payoff from the tournament and the second period is $\Pi+\left(1-\alpha_{h}\right) \Pi_{h}$ with $\Pi$ being described by (24). Hence, he has to solve

$$
\begin{gathered}
\max _{w_{1}^{h}, w_{1}^{l}}\left[\gamma_{h} \lambda\left(n a_{h}\right)+\gamma_{l} \lambda\left(n a_{l}\right)\right]\left(\mu_{H}-\mu_{L}\right)+2 \mu_{L}-w_{1}^{h} P_{h}-w_{1}^{l} P_{l}+\left(1-\alpha_{h}\right) \Pi_{h} \\
\text { subject to } \quad \frac{w_{1}^{p}}{n} \gamma_{p} \Delta F \lambda^{\prime}\left(n a_{p}\right)=c^{\prime}\left(a_{p}\right) \quad(p=h, l) .
\end{gathered}
$$

Call this alternative separation. If, on the other hand, $E$ decides to select 
plants via a shutdown contest, he must solve

$$
\begin{gathered}
\max _{w_{1}^{h}, w_{1}^{l}}\left[\gamma_{h} \lambda\left(n a_{h}\right)+\gamma_{l} \lambda\left(n a_{l}\right)\right]\left(\mu_{H}-\mu_{L}\right)+2 \mu_{L}-w_{1}^{h} P_{h}-w_{1}^{l} P_{l} \\
+\left(1-\alpha_{h}\right) \Pi_{h} P_{h}+\left(1-\alpha_{l}\right) \Pi_{l} P_{l} \\
\text { subject to } \quad\left(\frac{\alpha_{p} \Pi_{p}}{n}-\bar{v}_{p}+\frac{w_{1}^{p}}{n}\right) \gamma_{p} \Delta F \lambda^{\prime}\left(n a_{p}\right)=c^{\prime}\left(a_{p}\right) \quad(p=h, l) .
\end{gathered}
$$

Recall that $\alpha_{l}<\alpha_{h}$. Employer $E$ would be strictly better off from a shutdown contest if

$$
\left(1-\alpha_{h}\right) \Pi_{h}=\left(1-\alpha_{l}\right) \Pi_{l} \Leftrightarrow \frac{\Pi_{h}}{\Pi_{l}}=\frac{1-\alpha_{l}}{1-\alpha_{h}}=: \hat{\Pi} .
$$

In this situation, the selection decision would not influence $E$ 's second-period payoffs. Hence, from a pure selection perspective $E$ would be indifferent between separation and shutdown contest. However, under a shutdown contest $E$ could always implement the same or even higher effort levels at lower costs compared to separation. Let, in particular, $w_{1}^{h *}$ and $w_{1}^{l *}$ denote the optimal winner prizes under separation and $\left(a_{h}^{*}, a_{l}^{*}\right)$ the corresponding effort levels. If $w_{1}^{p *}>\alpha_{p} \Pi_{p}-n \bar{v}_{p}(p \in\{h, l\})$, then $E$ could implement $\left(a_{h}^{*}, a_{l}^{*}\right)$ under a shutdown contest as well and, at the same time, save implementation costs $\alpha_{p} \Pi_{p}-n \bar{v}_{p}$ at plant $p$. If $w_{1}^{p *}<\alpha_{p} \Pi_{p}-n \bar{v}_{p}(p \in\{h, l\})$, employer $E$ would even implement higher efforts at plant $p$ and save costs $w_{1}^{p *}$. Note that these higher effort levels are not a problem for $E$. As workers earn strictly positive rents in the given setting with limited liability, these higher effort levels would increase E's profits and reduce the workers' rents. If $\frac{\Pi_{h}}{\Pi_{l}}>\hat{\Pi}$, separation and shutdown contest will not yield identical second-period payoffs for $E$. However, if $\frac{\Pi_{h}}{\Pi_{l}}$ is not too large compared to $\hat{\Pi}$, employer $E$ 's benefit from saving implementation costs will be stronger than a possible disadvantage from uncertain selection. In other words, there is a cut-off $\bar{\Pi}>\hat{\Pi}$ so that a shutdown contest dominates separation from $E$ 's point of view, if $\frac{\Pi_{h}}{\Pi_{l}}<\bar{\Pi}$.

(b) Let $w_{1}$ denote the uniform winner prize of both plants in case of an un- 
verifiable winner. E's maximization problem is described by the Lagrangian

$$
\begin{aligned}
L\left(a_{h}, a_{l}, w_{1}\right)= & {\left[\gamma_{h} \lambda\left(n a_{h}\right)+\gamma_{l} \lambda\left(n a_{l}\right)\right]\left(\mu_{H}-\mu_{L}\right)+2 \mu_{L}-w_{1} } \\
& +\vartheta_{1} \cdot\left(\frac{w_{1}}{n} \gamma_{h} \Delta F \lambda^{\prime}\left(n a_{h}\right)-c^{\prime}\left(a_{h}\right)\right) \\
& +\vartheta_{2} \cdot\left(\frac{w_{1}}{n} \gamma_{l} \Delta F \lambda^{\prime}\left(n a_{l}\right)-c^{\prime}\left(a_{l}\right)\right)
\end{aligned}
$$

with $\vartheta_{1}$ and $\vartheta_{2}$ as multipliers. As optimality conditions we obtain

$$
\begin{aligned}
\gamma_{h} \lambda^{\prime}\left(n a_{h}\right) n\left(\mu_{H}-\mu_{L}\right)+\vartheta_{1}\left(\frac{w_{1}}{n} \gamma_{h} \Delta F \lambda^{\prime \prime}\left(n a_{h}\right) n-c^{\prime \prime}\left(a_{h}\right)\right) & =0 \\
\gamma_{l} \lambda^{\prime}\left(n a_{l}\right) n\left(\mu_{H}-\mu_{L}\right)+\vartheta_{2}\left(\frac{w_{1}}{n} \gamma_{l} \Delta F \lambda^{\prime \prime}\left(n a_{l}\right) n-c^{\prime \prime}\left(a_{l}\right)\right) & =0 \\
-1+\frac{\vartheta_{1}}{n} \gamma_{h} \Delta F \lambda^{\prime}\left(n a_{h}\right)+\frac{\vartheta_{2}}{n} \gamma_{l} \Delta F \lambda^{\prime}\left(n a_{l}\right) & =0 .
\end{aligned}
$$

Using the incentive constraints to substitute for $\frac{w_{1}}{n} \gamma_{p} \Delta F=\frac{c^{\prime}\left(a_{p}\right)}{\lambda^{\prime}\left(n a_{p}\right)}$ in the first two equations $(p=h, l)$ and rewriting yields

$$
\begin{gathered}
\gamma_{h} \lambda^{\prime}\left(n a_{h}\right)\left(\mu_{H}-\mu_{L}\right)=\frac{\vartheta_{1} \lambda^{\prime}\left(n a_{h}\right)}{n} c^{\prime}\left(a_{h}\right) \Psi\left(a_{h}\right) \\
\gamma_{l} \lambda^{\prime}\left(n a_{l}\right)\left(\mu_{H}-\mu_{L}\right)=\frac{\vartheta_{2} \lambda^{\prime}\left(n a_{l}\right)}{n} c^{\prime}\left(a_{l}\right) \Psi\left(a_{l}\right) \\
\frac{\vartheta_{1} \lambda^{\prime}\left(n a_{h}\right)}{n} \gamma_{h} \Delta F+\frac{\vartheta_{2} \lambda^{\prime}\left(n a_{l}\right)}{n} \gamma_{l} \Delta F=1 .
\end{gathered}
$$

Since $\gamma_{p} \Delta F<\frac{1}{2}(p=h, l)$ we obtain from the third equation that at least one of the two expressions $\frac{\vartheta_{1} \lambda^{\prime}\left(n a_{h}\right)}{n}$ and $\frac{\vartheta_{2} \lambda^{\prime}\left(n a_{l}\right)}{n}$ is larger than one. Hence, using Lemma 1, comparison of the first two equations with (11) points out that at least one of the optimal efforts $a_{h}^{*}$ and $a_{l}^{*}$ is smaller than the corresponding first-best level, due to the concavity of the welfare function per plant. Note that the rewritten incentive constraints $\frac{n}{w_{1} \Delta F}=\frac{\gamma_{h} \lambda^{\prime}\left(n a_{h}\right)}{c^{\prime}\left(a_{h}\right)}=\frac{\gamma_{l} \lambda^{\prime}\left(n a_{l}\right)}{c^{\prime}\left(a_{l}\right)}$ together with the first two equations imply that

$$
\frac{\vartheta_{1} \lambda^{\prime}\left(n a_{h}\right)}{n} \Psi\left(a_{h}\right)=\frac{\vartheta_{2} \lambda^{\prime}\left(n a_{l}\right)}{n} \Psi\left(a_{l}\right)>1 .
$$

Therefore, $a_{p}^{*}<a_{p}^{F B}(p=h, l)$. 
If the tournament winner is not verifiable, the same arguments hold as in the last paragraph of the proof of Proposition 3. Hence, $E$ always prefers separation of selection and incentives to a shutdown contest.

\section{Proof of Proposition 5:}

Case (a) refers to the situation with government $G_{l}$ having higher expected costs from plant closing: $k_{l}>k_{h} \Leftrightarrow\left(1-\phi_{l}\right) n_{l}>\left(1-\phi_{h}\right) n_{h}$. Together with $r_{h}<r_{l}$ we have to differentiate between six possible constellations: If $k_{h}<k_{l}<r_{h}<r_{l}$ or $k_{h}<r_{h}<k_{l}<r_{l}$, neither government will bid for the decision which plant to be closed since $k_{p}<r_{p}(p=h, l)$. If $r_{h}<k_{h}<k_{l}<r_{l}$, then government $G_{l}$ will be passive. Government $G_{h}$ bids its reserve price $r_{h}$, if and only if $r_{h}$ is smaller than the expected costs from remaining passive so that $E$ organizes a shutdown contest:

$$
r_{h}<P_{l} \cdot k_{h}
$$

In case of $k_{h}<r_{h}<r_{l}<k_{l}$ we have the opposite situation with $G_{h}$ being passive and $G_{l}$ bidding $r_{l}$, if and only if

$$
r_{l}<P_{h} \cdot k_{l}
$$

In the two remaining constellations, $r_{h}<k_{h}<r_{l}<k_{l}$ and $r_{h}<r_{l}<k_{h}<k_{l}$, both bidders will be active. Note that $E$ is indifferent between the following three outcomes: organizing a contest between the plants, selling the closing decision to government $G_{l}$ at price $r_{l}$, and selling to $G_{h}$ at price $r_{h}$. However, a situation with $b_{l}=r_{l}$ and $b_{h}=r_{h}$ cannot be an equilibrium. It would be rational for the bidders to incrementally counterbid each other (i.e., $G_{p}$ bids $b_{p}=r_{p}+\varepsilon$ so that $G_{\hat{p}}$ responds by offering $b_{\hat{p}}=r_{\hat{p}}+2 \varepsilon$; now $G_{p}$ bids $b_{p}=r_{p}+3 \varepsilon$ and so on with $\varepsilon \rightarrow 0$ and $\left.p, \hat{p}=h, l ; p \neq \hat{p}\right)$. Upbidding stops when one party $G_{\hat{p}}$ has reached $b_{\hat{p}}=r_{\hat{p}}+\left(k_{\hat{p}}-r_{\hat{p}}\right)=k_{\hat{p}}$. The other bidder (i.e., the government with the higher spread $k_{p}-r_{p}$ ) bids its reserve price plus the opponent's spread (i.e., $b_{p}=r_{p}+\left(k_{\hat{p}}-r_{\hat{p}}\right)=k_{\hat{p}}+r_{p}-r_{\hat{p}}$ with $\left.r_{l}-r_{h}=\left(1-\alpha_{h}\right) \Pi_{h}-\left(1-\alpha_{l}\right) \Pi_{l}\right)$ and wins the auction by the tie-breaking rule. 
Case (b) deals with $k_{h}>k_{l} \Leftrightarrow\left(1-\phi_{h}\right) n_{h}>\left(1-\phi_{l}\right) n_{l}$. If $k_{l}<k_{h}<$ $r_{h}<r_{l}$, both bidders remain passive. In the four situations $k_{l}<r_{h}<k_{h}<r_{l}$, $r_{h}<k_{l}<k_{h}<r_{l}, k_{l}<r_{h}<r_{l}<k_{h}$ and $r_{h}<k_{l}<r_{l}<k_{h}$ bidder $G_{l}$ is passive. $G_{h}$ will become active and bid $r_{h}$, if and only if this reserve price is smaller than the expected costs from accepting a shutdown contest:

$$
r_{h}<P_{l} \cdot k_{h}
$$

Finally, if $r_{h}<r_{l}<k_{l}<k_{h}$ there will be incremental counterbidding by both governments, but $G_{h}$ unambiguously wins due to $k_{h}-r_{h}>k_{l}-r_{l}$. The winning bid is $r_{h}+\left(k_{l}-r_{l}\right)=k_{l}-\left[\left(1-\alpha_{h}\right) \Pi_{h}-\left(1-\alpha_{l}\right) \Pi_{l}\right]$. 


\section{References}

Associated Press (2005): GM Slashing 30,000 Jobs, Closing Plants. November 21, 2005, http://www.msnbc.msn.com/id/10138507/

Bernard, A.B. and J.B. Jensen (2007): Firm Structure, Multinationals, and Manufacturing Plant Deaths. Review of Economics and Statistics 89, 193-204.

Brainard, S.L. (1994): Last One Out Wins: Trade Policy in an International Exit Game. International Economic Review 35, 151-172.

Brainard, S.L. and D. Martimort (1997): Strategic Trade Policy with Incompletely Informed Policymakers. Journal of International Economics 42, 33-65.

Brander, J.A. (1995): Strategic Trade Policy. In Grossman, G. and K. Rogoff (eds.): Handbook of International Economics, Volume III, Elsevier, 1395-1455.

Brander, J.A. and B.J. Spencer (1985): Export Subsidies and International Market Share Rivalry. Journal of International Economics 18, 83-100.

Bunkley, N. (2009): G.M. Designates 14 Plants for Closing. New York Times, June 1, 2009, http://www.nytimes.com/2009/06/02/business/ 02union.html

Cassing, J.H. and A.L. Hillman (1986): Shifting Comparative Advantage and Senescent Industry Collapse. American Economic Review 76, 516523.

Deily, M.E. (1991): Exit Strategies and Plant-Closing Decisions: The Case of Steel. RAND Journal of Economics 22, 250-263.

Dempsey, J. (2009): Freshly Minted Opel Deal Draws Critics. New York Times, September 13, 2009, http://www.nytimes.com/2009/09/14/business/global/14opel.html 
Dixit, A.K. and A.S. Kyle (1985): The Use of Protection and Subsidies for Entry Promotion and Deterrence. American Economic Review 75, $139-152$.

Drago, R., Garvey, G.T. and G.K. Turnbull (1996): A Collective Tournament. Economics Letters 50, 223-227.

Ghemawat, P. and B. Nalebuff (1985): Exit. RAND Journal of Economics 16, 184-194.

Gürtler, O. (2006): A Collective Tournament under (Un)Limited Liability. Economic Issues 11, 1-18.

Gürtler, O. (2008): On Sabotage in Collective Tournaments. Journal of Mathematical Economics 44, 383-393.

Hargreaves, S. (2009): GM Plant Closings: 20,000 Job Cuts. CNNMoney.com, June 1, 2009, http://money.cnn.com/2009/06/01/news/companies/gm_ facilities/index.htm?postversion $=2009060116$

Hart, O. and B. Holmström (1987): The Theory of Contracts. In Bewley, T.F. (ed.): Advances in Economic Theory, Fifth World Congress. Cambridge University Press, 71-155.

Jolly, D. (2010): G.M. Starts Revamp in Europe by Closing an Opel Plant. New York Times, January 21, 2010, http://www.nytimes.com/2010/01/ 22/business/global/ 22opel.html

Jolly, D. and J. Dempsey (2009): G.M. Won’t Close Germany's Opel Plants. New York Times, November 25, 2009, http://www.nytimes.com/2009/ 11/26/business/global/26opel.html

Kirkham, J.D. and H.D. Watts (1997): The Influence of Plant Profitability on Plant Closures in Multi-Locational Firms. Growth and Change 28, 459-474.

Konrad, K.A. (2000): Trade Contests. Journal of International Economics $\mathbf{5 1}, 317-334$. 
Konrad, K.A. (2009): Strategy and Dynamics in Contests, Oxford University Press: Oxford, New York.

Lieberman, M.B. (1990): Exit from Declining Industries: "Shakeout" or "Stakeout"? RAND Journal of Economics 21, 538-554.

Marino, A.M. and J. Zabojnik (2004): Internal Competition for Corporate Resources and Incentives in Teams. RAND Journal of Economics 35, $710-727$.

Reynolds, S.S. (1988): Plant Closings and Exit Behaviour in Declining Industries. Economica 55, 493-503.

Richbell, S.M. and H.D. Watts (2000): Plant Closures in Multiplant Manufacturing Firms: Adding an International Perspective. Management Decision 38, 80-88.

Stafford, H.A. (1991): Manufacturing Plant Closure Selections within Firms. Annals of the Association of American Geographers 81, 51-65.

Ward's Auto World (1992): GM Says It'll String Out Plant Closing Schedules, March 28, 1992, 22.

Watts, H.D. and J.D. Kirkham (1999): Plant Closures by Multi-locational Firms: A Comparative Perspective. Regional Studies 33, 413-424.

Whinston, M.D. (1988): Exit with Multiplant Firms. RAND Journal of Economics 19, 74-94.

Wintrobe, R. and A. Breton (1986): Organizational Structure and Productivity. American Economic Review 76, 530-538.

Wolfstetter, E. (1999): Topics in Microeconomics. Cambridge University Press. 